\title{
Some affixes are roots, others are heads
}

\author{
Ava Creemers ${ }^{1} \cdot$ Jan Don $^{2}$ (D) $\cdot$ Paula Fenger $^{3}$
}

Received: 20 May 2014 / Accepted: 22 March 2017 / Published online: 5 July 2017

(C) The Author(s) 2017. This article is published with open access at Springerlink.com

\begin{abstract}
A recent debate in the morphological literature concerns the status of derivational affixes. While some linguists (Marantz 1997, 2001; Marvin 2003) consider derivational affixes a type of functional morpheme that realizes a categorial head, others (Lowenstamm 2015; De Belder 2011) argue that derivational affixes are roots. Our proposal, which finds its empirical basis in a study of Dutch derivational affixes, takes a middle position. We argue that there are two types of derivational affixes: some that are roots (i.e. lexical morphemes) and others that are categorial heads (i.e. functional morphemes). Affixes that are roots show 'flexible' categorial behavior, are subject to 'lexical' phonological rules, and may trigger idiosyncratic meanings. Affixes that realize categorial heads, on the other hand, are categorially rigid, do not trigger 'lexical' phonological rules nor allow for idiosyncrasies in their interpretation.
\end{abstract}

Keywords Derivational affixes · Distributed morphology $\cdot$ Stress-behavior · Categorial flexibility $\cdot$ Phasal spell-out

J. Don

j.don@uva.nl

\section{A. Creemers}

creemers@sas.upenn.edu

P. Fenger

paula.fenger@uconn.edu

1 Department of Linguistics, University of Pennsylvania, 3401-C Walnut Street, Suite 300,

C Wing, Philadelphia, PA 19104-6228, USA

2 Department of Dutch Linguistics, Universiteit van Amsterdam, Spuistraat 134,

1012 VB Amsterdam, The Netherlands

3 University of Connecticut, Department of Linguistics, 365 Fairfield Way, Unit-1145, Room 368, Storss, CT, 06269, USA 


\section{Introduction}

A recent debate in Distributed Morphology ${ }^{1}$ (Halle and Marantz 1993; Harley and Noyer 1999) concerns the status of derivational affixes. In this paper we propose an adaptation of two influential proposals in the literature on the basis of a detailed analysis of Dutch data. One of these proposals (Marantz 1997, 2001; Marvin 2003, 2013) considers derivational affixes a type of functional morpheme that realizes a categorial head, while the other (Lowenstamm 2015; De Belder 2011) argues that derivational affixes are roots. Our proposal takes a middle position. We argue that there are two types of derivational affixes: some that are roots and others that are categorial heads.

Marantz (2001) proposes that the category of words does not project from the lexicon, but rather follows from category-determining functional heads. Derivational affixes are seen as the realization of these 'little x' heads. In a structure such as (1), an uncategorized root-element 'becomes' an adjective by means of the functional head that is merged with this root. This head could be realized by a vocabulary item, such as $-i c$.

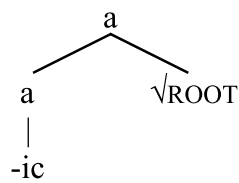

Combining this idea with a phase-based syntax (Chomsky 2000, 2001), Marantz $(2001,2007)$ proposes that each categorial head, and consequently each derivational affix, introduces a phase. Cyclic phonological effects, known since Sound Pattern of English (SPE; Chomsky and Halle 1968), could be made to follow from the resulting phase-based structure of words. This proposal is further developed in Marvin (2003).

However, Lowenstamm (2015) convincingly argues that Marvin's proposal cannot explain the phonologically different behavior of stress-shifting (+-boundary in SPE) and stress-neutral (\#-boundary) affixes. The crucial point of the criticism is that if every categorial head introduces a phase, the morphology cannot make the required distinction between structures containing stress-neutral affixes and structures containing stress-shifting affixes.

Moreover, both Lowenstamm (2015) and De Belder (2011) independently observe that in English and Dutch respectively, the same derivational affix does not always realize the same categorial head; rather, derivational affixes can be flexible between adjectives and nouns. Examples for English and Dutch are given in (2) and (3).

$$
\begin{array}{ll}
\text { a. } & -i a n]_{\mathrm{A}} \\
& \text { reptile-ian } \\
& \text { reptile-IAN }
\end{array}
$$

b. $\quad-i a n]_{\mathrm{N}}$

[English]

librar-ian

library-IAN

\footnotetext{
${ }^{1}$ We will focus on DM models here, but the status of derivational affixes is a more general debate in all models of morphology that separate the syntactic and phonological content of morphemes, such as Borer (2005a, 2005b).
} 

a. $\quad-a a t]_{\mathrm{A}}$
accur-aat
ACCUR-AAT
'accurate'

b. $\quad-a a t]_{\mathrm{N}}$

[Dutch]

kandid-aat

KANDID-AAT

'candidate'

Clearly, this flexible behavior of affixes is at odds with the assumption that affixes realize categorial heads. One would be forced to assume that there are two affixes -ian, one realizing an adjectival head and the other realizing a nominal head. However, since there are many more affixes that display such flexible behavior, this would be purely coincidental in an analysis that treats all affixes as the spell-out of categorial heads.

Therefore, Lowenstamm and De Belder take a more radical step and propose the following:

Affixes are roots (see Lowenstamm 2015:10).

Categorial flexibility can now immediately be explained, since in principle a root can combine with any categorial head. So, in their view, the English examples in (2a) and (2b) have the structures given in (5a) and (5b), respectively.

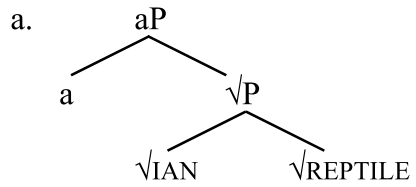

b.

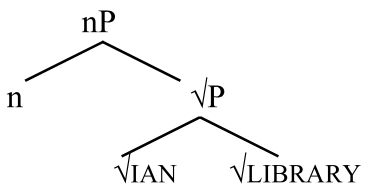

Moreover, Lowenstamm (2015) shows that (4) offers a solution to the problem that Marvin encounters in trying to account for the distinction between stress-shifting and stress-neutral affixes. Since derivational affixes are no longer categorial heads in his theory, they also no longer introduce phase-boundaries. Furthermore, a distinction can be made between affixes belonging to the root-domain and affixes that attach outside the root-domain. Assuming that the root-domain is the domain where the cyclic stress-rules apply, stress-shifting affixes (level-I affixes in Lexical Phonology, Kiparsky 1985) are assumed to merge in the first phase because they may only attach to root material. Stress-neutral affixes (level-II affixes), on the other hand, merge above the first categorizing head because they require a categorized phrase in their complement.

The claim that affixes are roots is an important move forward towards understanding the complex relation between morphology and phonology. However, there are several problems with such an analysis, which we aim to address and solve in this paper by adapting Lowenstamm's proposal.

One of the problems is that, contrary to what we would expect given the proposals by Lowenstamm and De Belder, only a relatively small subset of all derivational affixes are indeed categorially flexible: only $20 \%$ of the affixes in Dutch are (De Belder 2011). According to De Belder, it is a mere coincidence that is probably due to convention that all other affixes denote a single category. However, we think the fact that only a subset of the affixes show categorial flexibility should be taken as a grammatical property, rather than put aside as a mere coincidence. We, therefore, 
take flexibility as a litmus test for an affix to be considered a root. Affixes that do not show this property should be considered the realization of categorial heads (in line with Marantz's and Marvin's earlier proposals). So, we replace (4) with the weaker claim in (6):

Only affixes showing categorial flexibility are roots; all other derivational affixes realize functional heads.

Clearly such a move has further theoretical and empirical consequences. We will briefly mention the most important ones below, which together form the agenda for the remainder of this paper.

First, we are committed to show that by replacing (4) with (6), Lowenstamm's account of the distinction between stress-neutral and stress-shifting affixes can still be maintained. Second, taken at face value, four possible affix types are expected when affixes are cross-classified by stress-behavior (being stress-shifting or stress-neutral) and categorial flexibility (being flexible or rigid). However, only three types are actually empirically attested: (i) flexible affixes that have level-I properties (they may change stress-pattern and trigger lexical phonological rules) which we will provisionally call level-Ia affixes; (ii) non-flexible affixes that also have level-I properties which we will call level-Ib affixes; and (iii) non-flexible affixes that do not have levelI properties. Thus, there is a strong correlation between the behavior of affixes with respect to stress-rules and their categorial flexibility: those affixes that are categorially flexible are always stress-shifting. Such a correlation is unexpected in a theory that accepts (4), but this correlation does follow from the claim in (6) in our account: categorial flexibility is not a property of all affixes, but only of those affixes that are roots. We follow Lowenstamm (2015) in showing that only elements in the root phase can affect the stress-pattern of the base.

We argue that all flexible affixes are lexical morphemes, whereas all non-flexible affixes are functional morphemes. Our terminology here is based on the notion of 1- and f-morphemes, as proposed by Harley and Noyer (1999). ${ }^{2}$ We further argue that, in general, the level-I or level-II behavior of affixes follows from their position in the structure. This position results from their grammatical status (whether they are roots or not), and (following Lowenstamm) the selectional restrictions that these derivational affixes may have. The resulting proposal derives the fact that there are no affixes that are both stress-neutral and categorially flexible, and also accounts for the attested ordering restrictions between classes of affixes.

Of course, we are aware of the criticism level-ordered morphology has received with respect to affix order, articulated by Aronoff (1976), Aronoff and Sridhar (1983), Halle and Mohanan (1985) and Fabb (1988). However, most of this criticism is solved by earlier proposals (see e.g. Kiparsky 1982b). For the remaining part, it will become clear that our proposal allows for certain escapes to these predictions (without making the proposal immune to counter-evidence). Specifically, we follow Lowenstamm

\footnotetext{
${ }^{2}$ Below, we will use the term 'root' only as a theoretical term (as used in DM-theories) to refer to any uncategorized material (such as $\sqrt{ }$ REPTILE in (5a)), and not just bound stems (i.e. stems that cannot occur as a word). We will use the term 'bound stems' as a pre-theoretical term to refer to those roots that do not occur on their own (as opposed to 'free stems').
} 
in his proposal that some affixes are indifferent as to what they select as their complement: the complement might be either a root or a categorized structure. This allows us to account for the mixed behavior of these affixes without throwing away the insights we gain from this classification of affixes. ${ }^{3}$

Note, furthermore, that the predictions pertaining to affix order that derive from our proposal also differ somewhat from the predictions of 'traditional' level-ordering proposals (e.g. Siegel 1974). Since we argue that there is a distinction between three, rather than two, types of affixes, we also make specific predictions as to how these three types are ordered. In this respect, our proposal is much stronger, and consequently, has greater predictive power than traditional level-ordering analyses.

The paper is organized as follows. In Sect. 2 we empirically separate three classes of affixes in Dutch: level-Ia-affixes that are flexible and stress-shifting; secondly, level-Ib-affixes that are categorially rigid but also stress-shifting; and, thirdly, level-IIaffixes that are rigid and stress-neutral. In Sect. 3, we explain Lowenstamm's proposal that forms the basis for our approach in more detail. Sect. 4 offers our alternative account; here we also show how the proposal derives the Dutch data. In Sect. 5, open issues are discussed, and Sect. 6 concludes.

\section{Three types of affixes}

Our aim in this section is to show that there are three types of derivational affixes in Dutch. This typology is based on the following four criteria: categorial flexibility, behavior with respect to rules of stress-assignment, selectional properties, and respective order. As we have seen in the introduction, a property of derivational affixes is that some can be categorially flexible, while others cannot. We take this property as our first criterion to classify the Dutch affixes. SPE and later lexical models of word formation (e.g. Siegel 1974; Kiparsky 1982a, 1982b, 1985; Selkirk 1982; Giegerich 1999) make a distinction between two classes of affixes: stress-shifting or level-I affixes, and stress-neutral or level-II affixes. Different criteria have been employed to argue for level-I or level-II status, with the most prominent criterion being behavior with respect to stress-rules and other cyclic phonological rules. Level-I affixes are sensitive to these rules (thus potentially changing the stress-pattern), whereas level-II affixes are not. Another criterion is based on the selectional properties of affixes; level-I affixes can attach to bound stems, whereas level-II affixes cannot. Furthermore, the order of the affixes with respect to other affixes; stress-neutral affixes can only be found 'outside' of stress-shifting affixes. Also less prominent criteria have been put forward, such as their productivity (level-I affixes are generally less productive than level-II affixes), and transparency of meaning (level-I affixes are generally less transparent than level-II affixes). Importantly, these criteria cluster together: level-I affixes are stress-shifting, occur 'inside' level-II affixes and select bound roots. In sum, we use the properties given in (7) to set up a typology of derivational affixes in Dutch.

\footnotetext{
${ }^{3}$ For an alternative proposal that also seeks to derive the phonological behavior of affixes from the underlying syntactic structure, see Shwayder (2015).
} 
Table 1 Overview properties of affixes

\begin{tabular}{llll}
\hline Properties & Level-I & & Level-II \\
\cline { 3 - 4 } & $\mathrm{a}$ & $\mathrm{b}$ & \\
\hline Stress & Sensitive & Sensitive & Neutral \\
Flexibility & Flexible & Rigid & Rigid \\
Selectional requirements & Bound stems & Bound stems & Words \\
Relative position (with regard to stem) & 1 & 2 & 3 \\
\hline
\end{tabular}

\section{Criteria}
(a) flexibility
(b) stress behavior
(c) selectional properties
(d) relative order

The data are a combination of our own native intuitions, and data taken from de Haas and Trommelen (1993), Nieuwborg's reverse dictionary of Dutch (1969), and De Belder (2011). In Appendix 1 we list the affixes that we excluded from our data set; Appendix 2 lists all the affixes we included. We show in Sects. 2.1-2.4 that Dutch derivational affixes should be divided into three subsets that we have provisionally labeled level-Ia affixes, level-Ib affixes and level-II affixes. This labeling reflects the first outcome of this investigation: the traditional level-I affixes need to be split up into two types of affixes, level-Ia affixes and level-Ib affixes, as illustrated in Table 1. This three-way distinction renders a more precise division of derivational affixes, which has consequences for the theory of derivational affixes.

\subsection{Level-Ia affixes}

We will first discuss a subgroup of the affixes that were traditionally classified as level-I affixes, and which we provisionally call level-Ia affixes. We use this term in a theoretically neutral way to classify affixes that are characterized by the properties in (7a)-(7c) as follows: the affixes are flexible, stress-shifting and can attach to bound stems. Below we discuss each of these properties.

For example, consider the Dutch affixes -aal [al], -ief [if], -iel [il], and -iek [ik], which are the outermost derivational affixes in the words in (8)-(11). Some of these words can only be used as nouns ((a) examples), others are always adjectives ((b) examples), and others still can either be used as a noun or as an adjective ((c) examples). ${ }^{4}$ In the case of bound stems, the morphological analysis in these examples is based on the fact that both the affix and the stem occur in other forms.

\footnotetext{
${ }^{4}$ Throughout this paper bound lexical morphemes in examples are glossed in small caps (whether affixes or not). These morphemes have not been given a translation since their meaning or English equivalent is often impossible to determine. Note that the use of small caps in the glosses is not necessarily the same as the use of small caps in DM (indicating root status). Independent forms have standard typography and are glossed with a translation in English. Finally, the written form of the affixes is given in italics and, where applicable, phonological representations in square brackets.
} 
(8)
a. $\quad$ a. $-a a l]_{\mathrm{N}}$
miss-aal
$\mathrm{mis}_{\mathrm{N}}-\mathrm{AAL}$
'missal'
schand-aal
SCHAND-AAL
'scandal'

(9)

(10)

(11) $\begin{array}{ll}\text { b. } & \text { b. }-a a l]_{\mathrm{A}} \\ \text { puber-aal } \\ \text { adolescent }{ }_{\mathrm{N}}-\mathrm{AAL} \\ \text { 'pubertal' }\end{array}$

front-aal

front $_{\mathrm{N}}-\mathrm{AAL}$

'frontal'

b. $-i e f]_{\mathrm{A}}$

agress-ief

AGRESS-IEF

'aggressive'

mot-ief

MOT-IEF

'motive'

depress-ief

DEPRESS-IEF

'depressive'
a. $-i e k]_{\mathrm{N}}$
pan-iek
PAN-IEK
'panic'
eth-iek
ETH-IEK
'ethics'
b. $-i e l]_{\mathrm{A}}$
lab-iel
LAB-IEL
'unstable'
frag-iel
FRAG-IEL
'fragile'
c. $-a a l]_{\mathrm{N} / \mathrm{A}}$
liber-aal
LIBER-AAL
'liberal'
lok-aal
LOC-AAL
'local'

c. $-i e f]_{\mathrm{N} / \mathrm{A}}$

alternat-ief

ALTERNAT-IEF

'alternative'

retrospect-ief

retrospect $_{N}$-IEF

'retrospective'
c. $-i e l]_{\mathrm{N} / \mathrm{A}}$
mob-iel
MOB-IEL
'mobile'
text-iel
TEXT-IEL
'textile'
b. $-i e k]_{\mathrm{A}}$
canon-iek
canon $_{\mathrm{N}}$-IEK
'canonical'
diplomat-iek
diplomat $_{\mathrm{N}}$-IEK
'diplomatic'

From the data in (8) through (11), we conclude that the affixes -aal, -ief, -iel and -iek are all flexible. This property holds for a whole class of Romance affixes in Dutch (see Appendix 2). We come back to the Romance affixes that are not flexible in Sect. 2.2.

The second property of affixes in this class is that they may select bound stems, i.e. stems that cannot occur as a word. Consider the data in (8)-(11) again. Though these affixes do not exclusively attach to bound stems - many may, at least observationally, also attach to words-most of the bases of the affixes -aal, -ief, -iel and -iek are indeed bound stems (given in small caps); these bases cannot be used as a word. Again, this property generalizes to this group of affixes. In Sect. 2.3, we will show that this property contrasts with those affixes that may never attach to bound stems. Our analysis in Sect. 4.2 will derive this difference and we will argue that in cases in 
which a level-I affix seems to attach to a word (such as diplomat-iek in (11)), in fact, the affix also attaches to uncategorized material.

The third property of this class of affixes is the well-known fact about Dutch stress (see e.g. van der Hulst 1984; Kager 1989; Booij 1995; and in particular Langeweg 1985) that Romance affixes are always stress-shifting. More specifically, they are stress-bearing since most of them are so-called superheavy syllables which contain a rhyme consisting of a tense vowel (written as VV) followed by a consonant (VVC), or a lax vowel (written as V) followed by two consonants (VCC). These syllables only occur word-finally and always bear main stress. The final syllable will be stressed if an affix of this type is present. The affixes in the examples in (12) all attach to a bound stem, and in (13) to what looks like a word.

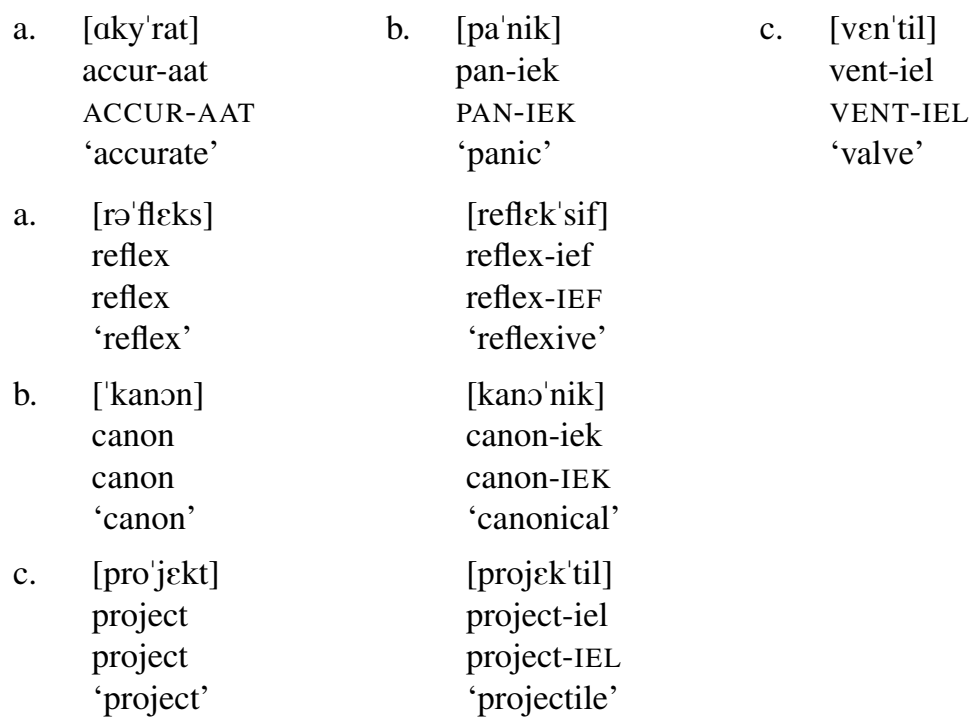

These affixes can be contrasted with superheavy affixes that do not attract stress (see Sect. 2.3).

To briefly sum up this section, we have shown that there is a class of affixes in Dutch (level-Ia in our terms) in which three properties converge: these affixes are all categorially flexible, they may attach to bound stems, and they are stress-shifting. In Sect. 2.4, we will show that these level-Ia affixes appear closer to the stem than the other two types of affixes to be discussed. We now turn to a second class of affixes: the level-Ib affixes.

\subsection{Level-Ib affixes}

The level-Ib affixes consist of both Romance and Germanic affixes. This class is characterized by the following properties: they are not categorially flexible, they may attach to bound stems, and they are stress-shifting. Note that at this point, the level-Ib affixes thus only differ from the level-Ia affixes in their non-flexibility (in Sect. 2.4, we will show that they also differ from level-Ia affixes with regard to their ordering: 
they crucially always occur outside of level-Ia affixes). We discuss the properties of level-1b affixes below.

First, the non-flexibility of level-Ib affixes is illustrated in (14) with the Dutch affixes -ig [əx], -(e)lijk [lək], -iteit [itcit], and -(is)eer [er] ${ }^{5}$ :

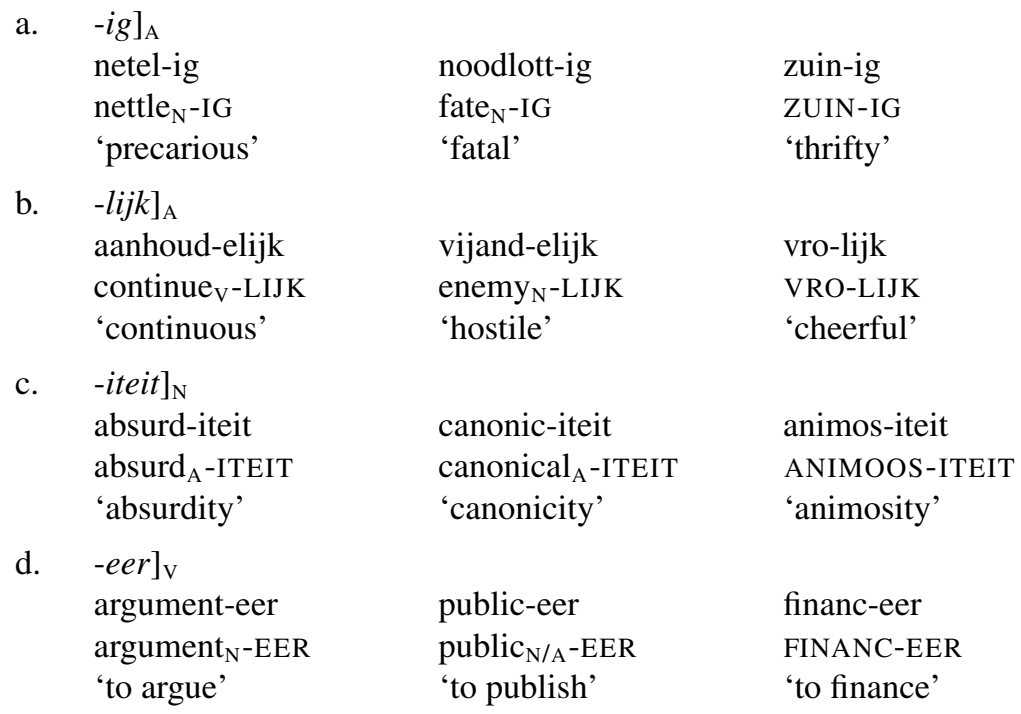

The examples in (14) show that the affixes -ig, -lijk, -iteit, and -eer are not categorially flexible: $-i g^{6}$ and -lijk always form adjectives, -iteit always forms nouns and -eer always forms verbs.

With respect to the second property, namely the selectional restrictions of the affixes, the rightmost examples in (14) show that these affixes may also attach to bound stems such as ZUIN, VRO, ANIMOOS, and FINANC. This behavior is similar to that of the traditional level-I affixes, which we discussed in the previous section. As in the case of level-Ia affixes, we will show in Sect. 4.2 that also in these cases in which the affix prima facie appears to attach to a word, in fact it attaches to uncategorized material.

Third, level-Ib affixes are stress-shifting. Both the Romance affixes -iteit and -eer carry main stress due to their superheavy syllables, as can be observed in the examples in (15a), (15b). For -ig and -lijk, it is important to note that these affixes both have a schwa as their kernel vowel. In Dutch, stress is on the penultimate syllable in underived words ending in a syllable with a schwa. This is also exactly what happens in forms with -ig and -lijk, showing that the stress patterns of complex words with

\footnotetext{
${ }^{5}$ The affix -lijk has an allomorph -elijk. The affix -eer has an allomorph -iseer. We have glossed allomorphs of the same morpheme in the same way. Allomorphy is further discussed in Sect. 5.1.2.

${ }^{6}$ In a few cases the affix -ig occurs in verbs: kruis-ig 'to crucify', sten-ig 'to stone' and pijn-ig 'to hurt (someone)'. We do not conclude from this that $-i g$ is a flexible affix because the number of adjectival forms far outnumbers these few verbal cases. If $-i g$ were truly flexible, we would expect far more adjectives that would have a phonologically identical verbal counterpart.
} 
-ig and -lijk follow from the stress rules for underived words (van der Hulst 1984; Kager 1989; Trommelen and Zonneveld 1989). The data in (15c) and (15d) illustrate this point.

\begin{tabular}{|c|c|c|c|}
\hline $\begin{array}{l}\text { a. } \\
\text { canono'nik] } \\
\text { canonical } \\
\text { 'canonical' }\end{array}$ & $\begin{array}{l}\text { [kanonisi'tcit] } \\
\text { canonic-iteit } \\
\text { canonical-ITEIT } \\
\text { 'canonicity' }\end{array}$ & $\begin{array}{l}\text { b. } \text { [argy'ment] } \\
\text { argument } \\
\text { argument } \\
\text { 'argument' }\end{array}$ & $\begin{array}{l}\text { [argymen'ter] } \\
\text { argument-eer } \\
\text { argument-EER } \\
\text { 'to argue' }\end{array}$ \\
\hline c. ['notlot] & [not'lotəx] & d. ['anhaut] & [an'haudələk] \\
\hline noodlot & noodlott-ig & aanhoud & aanhoud-elijk \\
\hline & fate-IG & continue & continue-LIJK \\
\hline 'fate' & 'fatal' & 'continue' & ‘continuous' \\
\hline
\end{tabular}

In a first attempt to analyze Dutch morphology in terms of level-ordering, Schultink (1980) identifies three Germanic affixes as stress-bearing: -ij, -in and -es. In our view these affixes belong to the level-Ib affixes, since they exclusively derive nouns and are thus rigid. Why - $i j$ bears main stress can be easily explained: it consists of a diphthong and final diphthongal syllables take primary stress in Dutch. A little more problematic is that -in and -es also take primary stress, since these affixes have a VC-syllable that is normally extrametrical in Dutch. Note however, that there are quite a few exceptions to this general tendency among underived words as well (Kager 1989). Consequently, many underived words end in a VCsyllable that receives main stress, and it therefore does not come as a surprise to find a few affixes that behave in the same way. We will come back to -in and -es in Sect. 2.4.

To summarize, the data in this and the previous subsection show that if we take flexibility into account, traditionally labeled level-I affixes need to be split into two classes. We separate level-Ia affixes, which are flexible, from level-Ib affixes, which are rigid.

Before we move on to the properties of level-II affixes, we will briefly discuss a few prefixes that may belong to the group of level-Ib affixes. The Germanic verbforming prefixes be-, ont-, and ver- and noun-forming ge- are not flexible and may attach to bound stems, as can be seen from the following examples in (16):

\begin{tabular}{|c|c|c|}
\hline \multicolumn{3}{|c|}{ a. $\quad[b e-\mathrm{v}$} \\
\hline [bə'dcik] & [bə' $\gamma$ rot] & [bə' $\gamma \mathrm{er}]$ \\
\hline be-dijk & be-groot & be-geer \\
\hline BE-dike $_{N}$ & BE-big $_{\mathrm{A}}$ & BE-GEER \\
\hline 'lay dikes' & 'budget' & 'desire' \\
\hline$[$ ont $-\mathrm{v}$ & & \\
\hline [ont.'er] & [ont'heiləx] & [ont'ber] \\
\hline ont-eer & ont-heilig & ont-beer \\
\hline ONT-honor $_{\mathrm{N}}$ & ONT-holy $_{\mathrm{A}}$ & ONT-BEER \\
\hline 'dishonor' & 'defile' & 'lack' \\
\hline
\end{tabular}




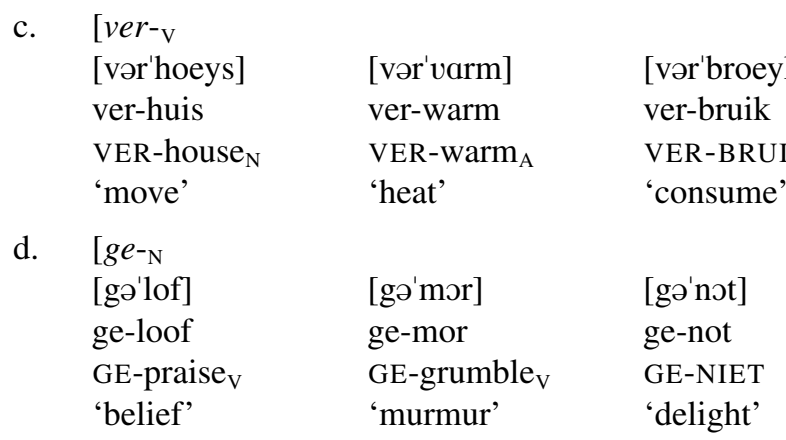

If these prefixes indeed belonged to this second group of affixes, we would also expect them to be stress-shifting. However, these prefixes show stress-neutral behavior. Furthermore, these affixes do not resyllabify either, as can be seen in the example onteer 'to dishonor' (16a), where the final [t] of the prefix does not become the onset of the second syllable. We claim that this behavior is not because these affixes are level-II affixes, but due to a combination of factors that mask their level-I status. In Sect. 4.2, we will explain this complex of factors that is orthogonal to the issues at hand. Thus setting aside the stress properties of these prefixes, we can conclude that they belong to the level-Ib affixes since they combine two properties: they are category-determining and they have the ability to attach to bound stems. We discuss the class of affixes that is traditionally called level-II affixes in the next section.

\subsection{Level-II affixes}

The third class of affixes, the level-II affixes, is characterized by the following properties: these affixes are non-flexible (i.e. each of them marks a single category), they only attach to categorized elements (and not to bound stems), and they are stressneutral. We will take the Germanic affixes -heid [heit], -ing [11], and -sel [səl] as examples of level-II affixes.

The first property is the non-flexibility of these affixes, which the data in (17) illustrate: all affixes mark a single category.

$\begin{array}{ll}\text { a. } & \text {-heid }]_{\mathrm{N}} \\ & \text { scheef-heid } \\ & \text { askew }_{\mathrm{A}} \text {-HEID } \\ \text { 'flexure' } \\ \text { schoon-heid } \\ \text { clean }{ }_{\mathrm{A}} \text {-HEID } \\ \text { 'beauty' }\end{array}$

$\begin{array}{ll}\text { b. } & - \text { loos }]_{\mathrm{A}} \\ & \text { bodem-loos } \\ \text { ground }_{\mathrm{N}} \text {-LOOS } \\ \text { 'bottomless' } \\ \text { leven-loos } \\ \text { life }_{\mathrm{N}} \text {-LOOS } \\ \text { 'lifeless' }\end{array}$
c. $\quad-s e l]_{\mathrm{N}}$ bak-sel bake $_{\mathrm{V}}-\mathrm{SEL}$ 'something baked' vertel-sel tell $\mathrm{V}_{\mathrm{S}}$-SEL 'tale'

Trommelen and Zonneveld (1986) take such data to demonstrate the workings of the Right-hand Head Rule (as proposed by Williams 1981) in Dutch and they claim that these suffixes determine the category of the derived word.

Second, with regard to selectional restrictions, the affixes in this third class attach to categorized material rather than bound stems. For many affixes this can be concluded from the fact that they always attach to words of the same category. This is 
shown in (17), where the category of each base is given. These affixes never attach to a word of another category nor do they attach to bound stems. The same is true for -baar, and -zaam (attach to verbs), -ster, and -schap (attach to nouns) and -te (attaches to adjectives). ${ }^{7,8}$ Other affixes in this class do not always attach to the same categorial base, as for instance the affix -er, which attaches to both verbs and nouns. However, no affixes in this class, including -er, ever attach to bound stems.

Thirdly, all affixes showing the properties discussed above are also stress-neutral. For affixes containing a superheavy syllable, this property is immediately clear from the fact that they are not stressed themselves (contrary to the affixes discussed in Sects. 2.1 and 2.2). Affixes with such segmental make-up would be predicted to carry main stress if they were stress-shifting. However, they are never stressed, nor does the position of stress change in their bases under affixation, as can be seen from the examples in (18).

$\begin{array}{ll}\text { a. } & \text { ['ardəx] } \\ \text { aardig } \\ \text { kind } \\ \text { 'kind' } \\ \text { b. } & \text { [bə'ant vort] } \\ & \text { beantwoord } \\ & \text { answer } \\ & \text { 'answer' }\end{array}$

\author{
['ardəxheit] \\ aardig-heid \\ kind-HEID \\ 'kindness' \\ [bə'antvortbar] \\ beantwoord-baar \\ answer-BAAR \\ 'answerable'
}

\begin{abstract}
${ }^{7}$ The female noun forming suffix -ster seems a bit more problematic since it sometimes seems to attach to verbs (verkoop $]_{\mathrm{V}}$-ster 'sale-STER', loop $]_{\mathrm{V}}$-ster 'walk-STER') and in other cases to nouns (wandelaar $]_{\mathrm{N}}$ ster 'walker-STER', handelaar $]_{\mathrm{N}}$-ster 'salesman-STER'). Don (2015), however, offers an analysis in which -ster is always denominal. In the apparent deverbal nouns, the denominal affix -er is deleted because of a rule of haplology. So, we may safely assume that -ster is a category-selecting affix.

${ }^{8}$ In the literature -baar and -zaam have often claimed to be stress-attracting affixes. The reason for this classification is that a compound verb such as op-los ['op.los] 'to solve' has stress on the left-hand part, whereas the form oplosbaar 'solvable' has main stress on the syllable immediately preceding -baar: [op.'los.bar]. However, Trommelen and Zonneveld (1989) point out that in Dutch, a verb-second language, these socalled separable compound verbs only show up in their non-separated form at the end of clauses. The final syllable is always de-accented in this position and the sentence accent (indicated in upper case letters below) falls on the prefinal syllable. Compare (ia) with (ib) below:
\end{abstract}

i. a. Ik weet dat jij vandaag nog WEG moet.
I know that you today yet away must
'I said you have to leave today.'
b. Ik weet dat jij dit vandaag OP lost.
I know that you this today on-solves
'I know that you will solve this today.'

Trommelen and Zonneveld (1989) claim that the stress in (ib) is not the result of word stress in oplossen but the result of sentence accent. Apart from these data there are no positions in the sentence where oplos is stressed as a word; therefore, if (ib) cannot tell us where the word stress is, we cannot be sure about the position of word stress in these constructions. The claim that -baar and-zaam are stress-attracting affixes is only based on the fact that after separable compounds, the word stress seems to shift. Since this fact is quite dubious, Trommelen and Zonneveld conclude that -baar and -zaam are stress-neutral. We assume that this analysis is on the right track, and thus, we classify -baar and -zaam as stress-neutral (see Kager 2000 for another possible analysis, which also renders these affixes stress-neutral). 
For the other affixes within this class, demonstrating their stress-neutrality is a little more complex as the observation that these affixes never influence the stress pattern of the base is insufficient: such 'stress-neutrality' could be the result of the specific segmental make-up of the affix in combination with the properties of the stress rules. Let us explain why this is the case.

The fact that we do not see a stress shift in monosyllabic stems followed by an affix that is not a superheavy syllable, is not very informative: Such a situation could either result from true stress-neutrality (the affix is not taken into account in the computation of the stress-position) or it could result from the fact that non-superheavy syllables never receive final stress (even if the affix is taken into account during stresscomputation). However, in the latter case we do expect them to be able to shift the stress towards the prefinal syllable given the right circumstances.

Consider the environment of a polysyllabic base without final stress and a suffix that is heavy (a VC-syllable). In Dutch, suffixes such as -ing [11]], -schap [sxap] and -dom [dom] consist of such a closed syllable (VC). Such syllables are extrametrical in final position (cf. Trommelen and Zonneveld 1989) and for that reason we would not expect them to carry main stress, even if they were stress-shifting. This implies that in order to show that these affixes are truly stress-neutral, we need a polysyllabic base with stress on the penultimate syllable. Adding a stress-shifting affix consisting of a VC-syllable to such a base would now change the stress-pattern since the affix would be extrametrical and the stress would fall on the prefinal syllable (i.e. the final syllable of the base). The examples in (19) show that such shifts do not occur with these affixes: If a level-II affix is attached, the stress does not shift. This shows that these affixes are indeed truly stress-neutral. ${ }^{9}$

\begin{tabular}{|c|c|c|}
\hline a. & $\begin{array}{l}\text { ['ratplex] } \\
\text { raadpleeg } \\
\text { consult } \\
\text { 'consult' }\end{array}$ & 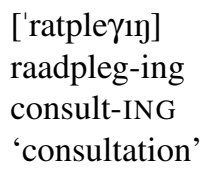 \\
\hline b. & $\begin{array}{l}\text { ['veiant] } \\
\text { vijand } \\
\text { enemy } \\
\text { 'enemy' }\end{array}$ & $\begin{array}{l}\text { ['veiantsxap] } \\
\text { vijand-schap } \\
\text { enemy-SCHAP } \\
\text { 'feud' }\end{array}$ \\
\hline c. & $\begin{array}{l}\text { ['hertox] } \\
\text { hertog } \\
\text { duke } \\
\text { 'duke' }\end{array}$ & 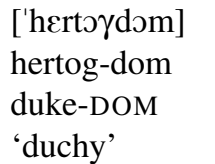 \\
\hline
\end{tabular}

\footnotetext{
${ }^{9}$ Another environment where we can see true stress behavior of these affixes is the following. Stress in Dutch is always on the syllable immediately preceding a final schwa (van der Hulst 1984; Kager 1989). Therefore, it is predicted that a stress-shifting affix containing a schwa shifts the stress to the syllable immediately preceding it. The following example shows that the affix -sel [səl] does not do this, and is therefore truly stress-neutral.
}

$\begin{array}{lll}\text { i. } & \text { ['oli] } & \text { ['olisəl] } \\ \text { olie } & \text { olie-sel } \\ \text { olie } & \text { cut.off-SEL } \\ \text { 'to oil' } & \text { 'unction' }\end{array}$


In summary, the class of level-II affixes is defined by the following properties: affixes in this class are all categorially rigid, they are word-selecting in the sense that they do not attach to bound stems, and they are stress-neutral.

Now that we have empirically established three classes of affixes (level-Ia, level$\mathrm{Ib}$, level-II), we can turn to their respective orderings in the next section. Before we do so, however, we would like to underline the fact that there is no affix type that is both flexible and stress-neutral. This is an important gap in need of an explanation.

\subsection{Affix ordering}

In this section, we take the three types of affixes into account, showing that the ordering of derivational affixes in Dutch follows the pattern given in (20).

$\begin{array}{llll}\text { S } & \text { A1 } & \text { A2 } & \text { A3 } \\ \text { STEM- } & \text { level-Ia } & \text { level-Ib } & \text { level-II }\end{array}$

The ordering in (20) demonstrates that level-Ia affixes (A1) are closer to the stem than level-Ib affixes (A2), which in turn appear 'inside' level-II affixes (A3). We will start by discussing level-Ib and level-II affixes in positions A2 and A3 respectively in (20).

The examples in (21) show that level-II affixes appear outside of level-Ib suffixes:

$$
\begin{aligned}
& \text { a. } \\
& \text { control-eer]-baar } \\
& \text { 'control-EER } \mathrm{A}_{\mathrm{A} 2}-\mathrm{BAAR}_{\mathrm{A} 3} \\
& \text { [financ-ier]-ing } \\
& \text { FINANC-EER }{ }_{\mathrm{A} 2}-\mathrm{ING}_{\mathrm{A} 3} \\
& \text { 'financing' } \\
& \text { [vriend-elijk]-heid } \\
& \text { friend-LIJK } \mathrm{A}_{\mathrm{A} 2}-\mathrm{HEID}_{\mathrm{A} 3} \\
& \text { 'friendliness' }
\end{aligned}
$$

b. * $\quad$ [control-baar $]$-eer control-BAAR $\mathrm{A}_{3}-\mathrm{EER}_{\mathrm{A} 2}$

*[financ-ing]-ier

FINANC-ING $\mathrm{A}_{3}-\mathrm{EER}_{\mathrm{A} 2}$

*[vriend-heid]-elijk

friend-HEID ${ }_{\mathrm{A} 3}-\mathrm{LIJK}_{\mathrm{A} 2}$

Level-II affixes such as -baar, -ing and -heid occur outside level-Ib affixes such as -eer, -ier and -elijk. The reverse never occurs: a level-Ib affix does not occur outside a level-II affix (21b). ${ }^{10}$

A potential counterexample involves the affix -es, which may occur after -aar. Compare the examples in (22) and (23):
a. [vin]
win
b. winn-aar win-ER
c. winn-ar-es
win-ER-ES
d. *winnaar-ster winner-STER
'to win'
'winner'
'female winner'
a. [van.dəl] wandel 'to walk'
b. wandel-aar walk-ER
c. *wandel-ar-es walk-ER-ES
d. wandelaar-ster walk-ER-STER 'walker' 'female walker'

\footnotetext{
${ }^{10} \mathrm{As}$ far as we are aware, there is one counterexample to this claim. The affix -lijk may occur in a few examples outside of the affix -schap. In Sect. 4.2 we show that the suffix -schap should be analyzed an affix that does not have specific selectional restrictions.
} 
The affix -aar in (23) is an allomorph of the affix -er that generally derives agentive nouns from verbs. According to our criteria, -er is a level-II affix. This implies that its allomorph -aar would also be a level-II affix. Above, we showed that -es is a levelIb affix, which would make winnares (22c) and similar examples problematic for our proposal as it seems that a level-Ib affix attaches 'outside' of a level-II affix. However, we have reason to believe that the examples in which -es occurs outside -aar are in fact morphologically simplex. Our argument is that under normal conditions -es cannot appear after -er or its allomorph -aar (hence the ungrammaticality of (23c)). The condition under which -aar normally surfaces is after a syllable containing a schwa, as is shown in (23b). These conditions are not met in (22), since here -aar shows up after a monosyllabic stem. There are a few more cases that are similar (Zwarts 1975). Precisely in those cases, and not in any other form derived with -aar, the suffix -es may follow. This may be taken as evidence that the few words with -aar after monosyllables are in fact underived. As such, the appearance of -es after these forms does not go against the generalization in (20). Moreover, its appearance in these forms is in line with the general distribution of -es, that occurs after underived stems, as in baron-es 'baroness', prins-es 'princess', et cetera.

Let us now turn to the ordering of the affixes in positions A1 and A3. As can be expected, and as also observed by Booij (1977), level-Ia affixes (A1) always occur inside level-II affixes (A3). Some examples are given in (24):

$$
\begin{aligned}
& \text { a. doc-iel-heid } \\
& \text { DOC-IEL }{ }_{\mathrm{A} 1}-\mathrm{HEID}_{\mathrm{A} 3} \\
& \text { 'docility' } \\
& \text { reflex-ief-heid } \\
& \text { reflex-IEF }{ }_{\mathrm{A} 1} \text {-HEID }{ }_{\mathrm{A} 3} \\
& \text { 'reflexivity' }
\end{aligned}
$$

b. $\quad *$ doc-heid-iel DOC-HEID $\mathrm{A}_{3}-\mathrm{IEL}_{\mathrm{A} 1}$

$$
\begin{aligned}
& { }^{*} \text { reflex-heid-ief } \\
& \text { reflex-HEID } \\
& \mathrm{A}_{3}-\mathrm{IEF}_{\mathrm{A} 1}
\end{aligned}
$$

These examples show that the level-II affix -heid (A3) occurs outside level-Ia affixes such as -iel and -ief (A1). However, such examples that show this ordering (stem-A1-A3) are rare due to several factors. First, quite a number of level-II affixes are deverbal (-baar, -zaam, -sel, -er). Given that there are no level-Ia affixes that derive verbs, this particular ordering prediction cannot be tested for these affixes. Second, level-II affixes such as -schap and -dom are far from productive: they only exist in a limited number of words. It seems to be the case that by the time the Romance stems entered the Dutch lexicon,-dom and -schap were no longer productive. Consequently, no examples exist in which Romance roots are internal to these nonproductive Germanic affixes. The illustration of the ordering generalization, therefore, is limited to denominal and deadjectival productive affixes.

The dearth of data of the type in (24) can be compensated for with data that contain all three types of affixes: level-II (A3) outside level-Ib affixes (A2) outside level-Ia affixes (A1). The evidence for the order between level-Ia affixes and level-II affixes is indirect in those cases, but not less relevant. We have listed several examples illustrating the predicted order between the affixes in (25). 


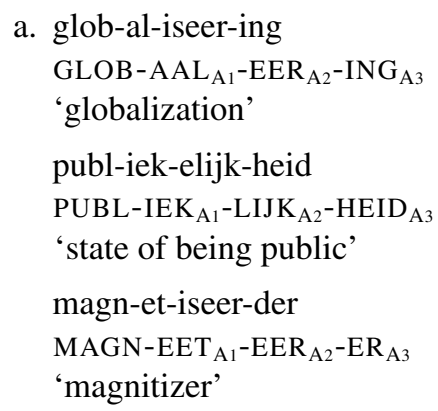

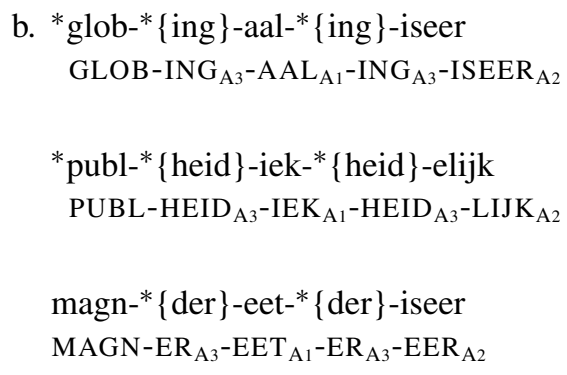

The examples in (25) show that level-II affixes such as -ing are ordered outside level$\mathrm{Ib}$ affixes such as -eer, and also outside level-Ia affixes such as -aal.

Finally, as is also implicitly shown in (25), it is expected that level-Ib affixes (A2), occur 'outside' level-Ia (A1). The examples in (26) once more illustrate that this is indeed the case. There are, to our knowledge, no exceptions to this ordering.
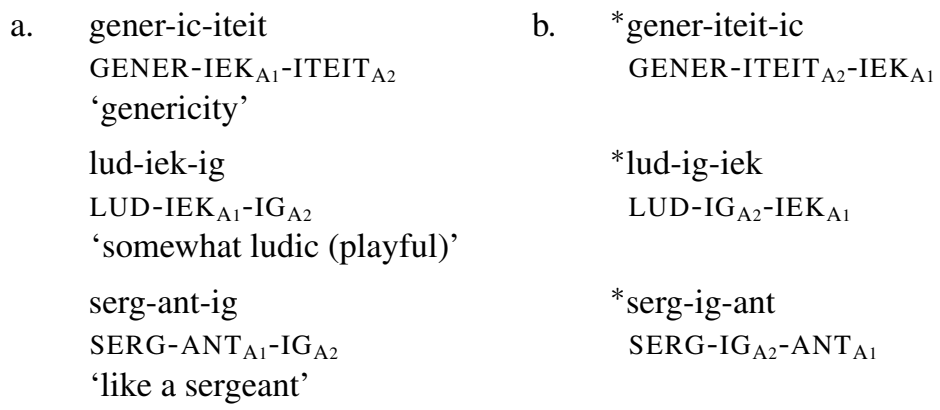

Again, the ordering cannot be reversed: the affixes -iteit, -ig, and -eer never occur inside any of the level-Ia affixes. To summarize, based on the data in (21)-(26) we have shown that the generalization in (20) holds: there is a strict ordering of the three classes of affixes.

Finally, we make some observations with respect to the ordering of the Germanic prefixes be-, ver- and ont-. We observed above (see the data in (16)) that these prefixes attach to bound stems, and that they are categorially rigid. Since no conclusions can be drawn from their stress-behavior, we provisionally classified these affixes as level-Ib. We may now observe that these prefixes occur both inside and outside other level-Ib affixes. The examples in (27b), (27d), (27f) are all verbs, showing that the verb-forming prefixes are the highest affixes in the structures, and attach 'outside' affixes such as -ig and -lijk, which we classified as level-Ib in Sect. 2.2.
a. zuin-ig
ZUIN-IG ${ }_{\mathrm{A} 2}$ 'frugal'
b. $\quad{ }_{\mathrm{v}}[b e-$
be-zuin-ig $\mathrm{BE}-\left[\mathrm{ZUIN}-\mathrm{IG}_{\mathrm{A} 2}\right]_{\mathrm{A}}$ 'to cut costs' 

c. werk-elijk 'real' work-ELIJK ${ }_{\mathrm{A} 2}$
d. $\quad$ [ver-
ver-werk-elijk
VER-[work-ELIJK $\left.\mathrm{A}_{\mathrm{A} 2}\right]_{\mathrm{A}}$
'to realize'
e. heil-ig
good- $\mathrm{IG}_{\mathrm{A} 2}$
'holy'
f. $\quad \mathrm{v}[$ ont -
ont-heil-ig
ONT-[good-IG $\left.\mathrm{A}_{2}\right]_{\mathrm{A}}$
'to defile'

In the examples in (28b), (28d) we see that the same prefixes occur inside these affixes:
BE-DERF
'decay'
a. be-derf
c. ver-driet
VER-DRIET
'sorrow'
b. $\quad$ [be-
[be-derf]-elijk
$[\mathrm{BE}-\mathrm{DERF}]_{\mathrm{V}}-\mathrm{LIJK}_{\mathrm{A} 2}$ 'perishable'
d. $\quad$ [ver-
[ver-driet]-ig
$[\text { VER-DRIET }]_{\mathrm{N}}-\mathrm{IG}_{\mathrm{A} 2}$
'sad'

The adjectives in (28) all show that the suffixes, rather than the verb-forming prefixes, are the highest attaching affixes. Thus, we may conclude that the Germanic prefixes occur both inside and outside other level-Ib affixes. Furthermore, we note that these Germanic prefixes are always inside level-II affixes, as demonstrated in (29).

$$
\begin{aligned}
& \text { a. } \\
& \mathrm{BE}_{\mathrm{A} 2} \text {-ride- } \mathrm{ER}_{\mathrm{A} 3} \\
& \text { 'rider' } \\
& \text { [ont-hoofd]-ing } \\
& \text { ONT }_{\mathrm{A} 2} \text {-head-ING } \mathrm{IN}_{\mathrm{A} 3} \\
& \text { 'beheading' } \\
& \text { [ver-warm]-baar } \\
& \text { VER } \\
& \text { 'heatable' }
\end{aligned}
$$

$$
\begin{aligned}
& \text { b. *be-[rijd-er] } \\
& \mathrm{BE}_{\mathrm{A} 2} \text {-drive- } \mathrm{ER}_{\mathrm{A} 3} \\
& \text { *ont-[hoofd-ing] } \\
& \mathrm{ONT}_{\mathrm{A} 2} \text {-head- } \mathrm{ING}_{\mathrm{A} 3} \\
& \text { *ver-[warm-baar] } \\
& \mathrm{VER}_{\mathrm{A} 2} \text {-heat-BAAR }{ }_{\mathrm{A} 3}
\end{aligned}
$$

For now we conclude that the ordering properties of these prefixes are in line with their level-Ib-status.

The picture that emerges from the previous three sections is that Dutch derivational affixes need to be divided into three rather than two groups of affixes. By taking categorial flexibility into account, we showed that the traditional group of stress-shifting level-I affixes has to be split into two types of affixes. We provided empirical evidence for the existence of a first group of (mainly Romance) categorially flexible 
Table 1 Overview properties of affixes (repeated)

\begin{tabular}{llll}
\hline Properties & Level-I & Level-II \\
\cline { 2 - 4 } & $\mathrm{a}$ & $\mathrm{b}$ & Neutral \\
\hline Stress & Sensitive & Sensitive & Rigid \\
Flexibility & flexible & Rigid & Words \\
Selectional requirements & Bound stems & Bound stems & 3 \\
Relative order (w.r.t. stem) & 1 & 2 & \\
\hline
\end{tabular}

affixes that we provisionally called level-Ia affixes, and a second group of (both Romance and Germanic) categorially non-flexible affixes that we called level-Ib affixes. The third group of affixes is the group of level-II affixes, which consist mainly of Germanic affixes, and are stress-neutral, non-flexible and (in contrast to both types of level-I affixes) not able to attach to bound stems. Note that affixes that are both stress-neutral and flexible are not attested in Dutch. The three types of derivational affixes and their properties were summarized in Table 1, repeated here for convenience.

Table 1 shows that a correlation exists between stress properties, selectional restrictions, and categorial flexibility. To account for this correlation, we will argue in the next section that there are two types of affixes, rather than one (as was previously proposed by a.o. Marantz 1997; Marvin 2003; Lowenstamm 2015; De Belder 2011). We first discuss Lowenstamm's proposal that affixes are roots rather than the spell-out of categorial heads. We show that it is not possible in existing proposals to account for the properties of Dutch derivational affixes. In Sect. 4 we formulate a new proposal that adds to and synthesizes previous proposals and can account for the Dutch data.

\section{Affixes as roots}

\subsection{Lowenstamm's proposal}

Recall from the introduction that in Lowenstamm's (2015) view, categorial flexibility is an inherent property of affixes. In this section, we will discuss Lowenstamm's proposal $^{11}$ stressing the advantages of his proposal over lexical proposals and Distributed Morphology (henceforth DM) that take derivational affixes to be the spellout of categorial heads. Furthermore, we will stress that despite the attractiveness of Lowenstamm's proposal, there are some aspects-both theoretical and empirical in nature-that we consider to be problematic.

As briefly discussed in the introduction, root-and-category proposals (Marantz 1997, 2001; Marvin 2003, 2013) take derivational affixes as the spell-out of cate-

\footnotetext{
${ }^{11}$ Just as Lowenstamm, De Belder (2011) also argues, for different reasons, that derivational affixes should be treated as roots rather than as the spell-out of categorial material. However, she does not focus on the distinction between level-I and level-II affixes and therefore we will not discuss her proposal in detail.
} 
gorial heads and assume that these categorial heads introduce the domains of phasal spell-out. Moreover, the domains of phasal spell-out are the same as the cycles of SPE. Lowenstamm (2015) argues that these assumptions cannot account for the distinction between level-I and level-II affixes.

Lowenstamm's argument runs as follows. In root-and-category models of morphology, such as DM, a separate functional head categorizes a root, as illustrated in (30).

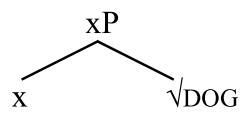

Furthermore, affixes are inserted 'late,' i.e. after the syntactic structure has been formed. Note that in SPE and lexical theories of morphology (a.o. Siegel 1974; Kiparsky 1982a, 1982b), the different behavior with regard to stress rules can be encoded as a property of the affixes since the morphological structure is projected from these affixes. But, as Lowenstamm argues, a theory that adheres to late spell-out must make different assumptions, since at the point of spell-out, the structure does not contain any phonological information. For example, the structure of atomicity (with stress shift) and atomicness (without stress shift) is the same, i.e. [ $\mathrm{n}[\mathrm{a}[\mathrm{n}[\sqrt{ } \mathrm{ATOM}]]]]$ at the relevant level of representation. There is no way in which the structure is projected from the affixes, since the affixes themselves are only inserted later, realizing the previously built structure. Since both atomicity and atomicness have the same underlying structure, one cannot rely on this structure to make the distinction between stress-shifting and stress-neutral affixes. To resolve this problem, Lowenstamm replaces the assumptions of Marantz (1997, 2001) and Marvin (2003, 2013) with the assumptions in (31):
a. Affixes are roots.
b. Level-I affixes have an uninterpretable feature $[u \sqrt{ }]$.
c. Level-II affixes have an uninterpretable feature [u xP].

Although Lowenstamm proposes that all affixes are roots (31a), they are different from true 1-morphemes (e.g. $\sqrt{ }$ DOG), because affixes always need a complement to project to the phrasal level. To account for this property of affixes, Lowenstamm proposes that all affixes have an uninterpretable feature that may be checked against either a root (31b) or a categorized structure (31c). These uninterpretable features do not involve a stipulative level-I or level-II feature (as they would in Lexical Morphology) because they are also necessary in order to account for the distribution of affixes: they are bound elements (32a) that come in two types, namely those that attach to uncategorized roots $(32 \mathrm{~b})$ and those that attach to categorized structures (32c). 


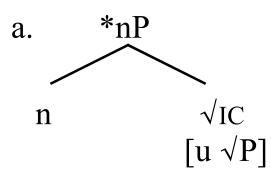

b.

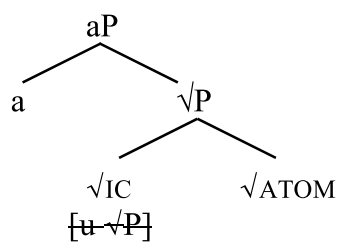

c.

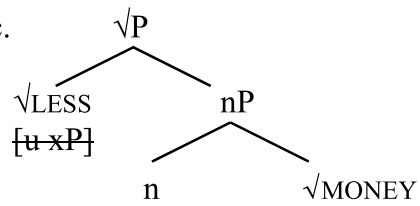

The difference in stress assignment between the two types of affixes is accounted for as follows. Lowenstamm assumes that any categorial head is a phase boundary (Marantz 2001). Cyclic stress rules apply in the first phase. In this way it follows that only affixes marked $[u \sqrt{ }]$ (such as -ity and -ic in (33a) below) can be stress-shifting: they occur below any categorial heads, and thus below the first phase boundary. In contrast, affixes that require a categorized structure, because they have an uninterpretable feature $[\mathrm{u} \mathrm{xP}]$, can only attach above a categorizing head (such as -ness in (33b)), and thus above a phasal head. In this structural position they will not be able to influence the spell-out of the first phase, hence their stressneutrality.
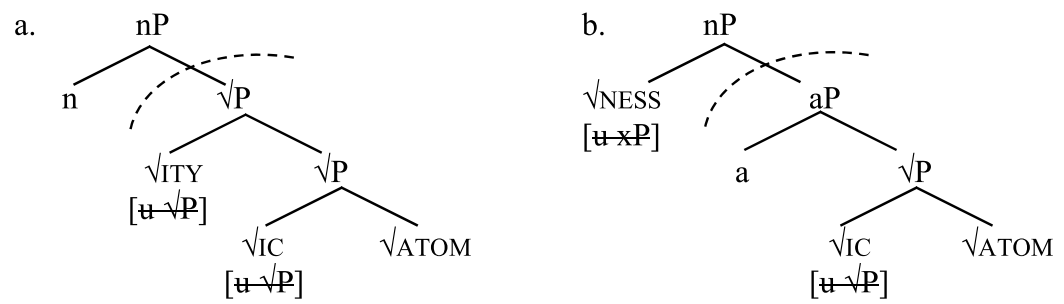

Because -ness and -ity have different feature specifications, the status of the part atomic differs when -ity or -ness attaches to it. The level-I affix -ity is not attached to the adjective atomic, but to a complex root $\sqrt{ }$ ATOMIC in (33a), whereas -ness attaches to the adjective atomic in (33b). Summarizing, we see that in Lowenstamm's proposal the stress behavior and selectional restrictions of level-I and level-II affixes is accounted for by their position in the structure, which results from their uninterpretable features.

We believe that Lowenstamm's proposal is an interesting alternative to DM approaches that take affixes as the spell-out of categorial material (Marantz 2001; Marvin 2003), and a step forwards in our understanding of affixal behavior. However, we also think that there are a few problematic aspects that may be solved once we allow for the possibility of different types of derivational affixes. Let us discuss these problematic aspects first as a step towards our proposal in Sect. 4. We start with a theoretical problem, after which we will discuss a closely-related empirical problem. 


\subsection{Issues with an affixes-as-roots analysis}

The theoretical problem involves the position of level-II affixes such as -ness in Lowenstamm's proposal. These affixes are assumed to have an uninterpretable feature [u xP] that can only be checked against a categorized structure. As a consequence, a structure in which -ness attaches to an uncategorized root, as in (34a), is ungrammatical (cf. Lowenstamm 2015:240 [ex. 20]). Therefore, the root $\sqrt{ }$ RED needs to be categorized before -ness attaches to the structure, as in (34b).

a.

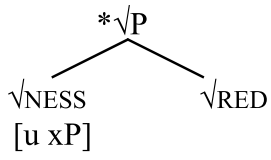

b.

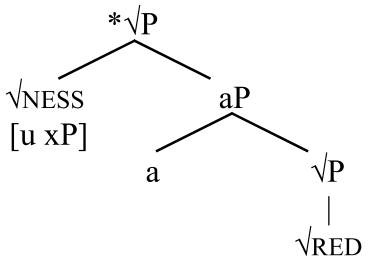

However, the structure in (34b) is also ungrammatical. Although the affix can successfully check its uninterpretable feature (against the aP), the structure is now uncategorized, and violates the following principle adopted by Lowenstamm:

Categories head roots, not vice versa. (Lowenstamm 2015:240, ex. (21))

In (34b), a root heads a structure in which it merges with a category, which renders this structure ungrammatical according to this principle. Lowenstamm proposes that the violation of (35) is resolved in the next step of this derivation. The whole root phrase (34b) merges with a categorial head, as in (36a), to which the head of the root phrase (i.e. the affix -ness) moves, (36b). As a result, the root-phrase no longer contains a head and is therefore rendered empty. This means that the aP is no longer headed by a root (compare Lowenstamm 2015:245 [ex. 36]).

a.

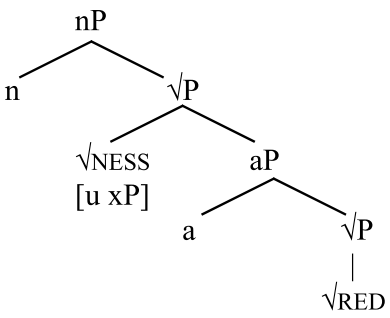

b.

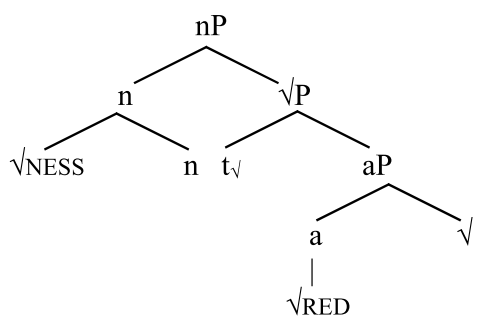

The movement in (36b) in Lowenstamm's analysis captures the stress-neutrality of any affix that carries the [u xP]-feature without violating the constraint in (35). However, we believe a less cumbersome analysis that captures the difference between stress-neutral and stress-shifting affixes is possible. An alternative analysis is that level-II affixes are in fact the spell-out of a categorial head. ${ }^{12}$

\footnotetext{
${ }^{12}$ In his discussion of Lowenstamm's proposal, Shwayder (2015) points out a potential problem. He argues that Lowenstamm cannot explain why -less in moneyless bears no stress at all. The reason is that since the root -less is not in the same domain for stress-assignment as the root money, one would expect some
} 
There are two main reasons for this alternative. First, if the level-II affix itself is not a root but the spell-out of a categorial head, then there is no illicit structure built in the first place, which would solve the issue arising in the structure in (36a). The second reason is directly linked to the empirical problem that not all affixes show categorially flexible behavior. Recall from Sect. 2 that all Dutch affixes that are stress-neutral are always non-flexible. In fact, De Belder (2011:152) has shown that only 20\% of Dutch derivational affixes are actually flexible. Even though we do not have the figures on flexibility for the English derivational affixes, English affixes such as -ity, -ness and -less do not show flexible behavior.

The proposal by Lowenstamm has no simple solution to ensure that objects such as (34b) will always be selected by $n$ (and not by $v$ or $a$ ); therefore, it is unexpected in his proposal that $80 \%$ of the affixes are always selected by the same categorial head. In addressing this issue, De Belder claims that the reason that the majority of the affixes in Dutch are non-flexible is 'sheer convention.' To solve this problem, we argue that the flexibility of affixes should not be taken as an inherent property of all derivational affixes. We will instead provide an explanation for the non-flexibility of most affixes, as we will propose that these affixes are not roots but are the spell-out of a categorial head. Their non-flexibility is then expected. This way, the distinction in the grammatical status of the affixes (root versus categorial head) separates flexible from non-flexible affixes, as well affixes that do introduce phasal boundaries from those that do not. The precise implementation of this idea will be given in the next section.

\section{Affixes: Roots and heads}

In Sect. 4.1, we lay out our assumptions that derive the three types of affixes: stressshifting flexible, stress-shifting rigid, and stress-neutral rigid. In Sect. 4.2, we derive the three different groups of affixes that were distinguished in Sect. 2 using the assumptions from Sect. 4.1. Section 5 will discuss some further consequences of our proposal.

\subsection{The proposal}

We propose that there are two types of affixes: 1(exical)-affixes, which are roots, and f(unctional)-affixes (following the terminology proposed by Harley and Noyer 1999), which are the spell-out of functional material. In particular, we claim that level-Ia affixes are all l-affixes, and that both level-Ib and level-II affixes are f-affixes, differentiated by their respective selectional restrictions. The proposal is summarized in (37). Below, each of the separate elements of the proposal will be explained in detail.

type of compound stress assignment (as for example in Harley 2009): both (root) domains will get stress separately and only one of the domains will receive main stress. See Embick (2014) and Shwayder (2015) for additional critical discussion of Lowenstamm's proposal. Our proposal inherits this problem to some extent but we have at least a somewhat more principled way of explaining this. In our proposal, an affix such as -less is not a root, but the spell-out of a categorial head and is, therefore, not a separate stressassignment domain. 
Table 2 Affix types

First phase

a. 1-affix

$[\mathrm{u} \sqrt{ } \mathrm{P}]$
Later phases

b. f-affixes

f-affixes

$[\mathrm{u} \sqrt{ } \mathrm{P}]$

[u XP]

f-affix [u x]

(i) There are two types of affixes: 1-affixes and f-affixes.

(ii) F-affixes can have different selectional requirements: $[\mathrm{u} \sqrt{ } \mathrm{P}],[\mathrm{u} \mathrm{xP}]$ or $[\mathrm{u} x]$.

(iii) Only cyclic complements of phase-heads are sent to the interfaces (Embick 2010).

The claim in (i) is our main contribution to the status of the affixes. The importance lies in the fact that we split up the traditional level-I affixes into two groups, as illustrated in Table 2.

Rather than claiming that all derivational affixes are roots (Lowenstamm 2015; De Belder 2011), or that all derivational affixes spell out a categorial head (Marantz 2001; Marvin 2003), we propose that there are both 1-affixes, which are roots (following Lowenstamm 2015; De Belder 2011), and f-affixes, which are the spell-out of functional heads (following Marantz 2001; Marvin 2003).

The division between 1-affixes and f-affixes immediately explains why not all affixes are flexible: only those that belong to the class of 1-affixes, i.e. roots, are categorially flexible. These roots subsume a subgroup of the traditional level-I affixes, namely those that we called level-Ia affixes. F-affixes are non-flexible by nature since they always spell out the same categorial heads. The latter group consists of a subgroup of level-I affixes (those that we called level-Ib affixes) and of all the level-II affixes.

Turning now to (37ii), we claim that the distinction between f-affixes at levelI and f-affixes at level-II resides in their selectional requirements. We propose that all level-I affixes (i.e. both the l-affixes and f-affixes of this level) attach to uncategorized roots, whereas level-II affixes attach to already categorized structures. We follow Lowenstamm (2015) in accounting for these different selectional requirements by means of feature checking. As shown in Sect. 3, Lowenstamm proposes that affixes have different features that need to be checked: level-I affixes have an uninterpretable root-feature $[\mathrm{u} \sqrt{ } \mathrm{P}]$, whereas level-II affixes need to check an uninterpretable category-feature $[\mathrm{u} x \mathrm{P}]$. Finally, it is also possible to have f-affixes with no specific selectional restrictions. That is, we allow affixes with a feature [u x] (again following Lowenstamm) that are satisfied by merger with any possible category or root. Such affixes occur both with roots and categorized structures, and moreover, show stressshifting behavior whenever they attach to roots, whereas they are stress-neutral when attaching to a categorized structure (see Sect. 4.2 for examples).

Now that we have laid out the first two elements of our proposal, we can see how these yield the required three-way split between (i) level-Ia affixes that are rootselecting 1-affixes, (ii) level-Ib affixes that are root-selecting f-affixes, and (iii) levelII affixes that are f-affixes attaching to categorized material (category-selecting f- 
affixes). We will now turn to the third element, that yields the split in phonological sensitivity of level-I and level-II affixes.

We propose, following Marantz (2001), that categorial heads are cyclic heads (37iii). We adopt a specific version of phase-based spell-out, as proposed by Embick (2010). According to Embick, Spell Out operates as follows:

a. (Spell Out 1) When a cyclic head $\mathrm{x}$ is merged, cyclic domains in the complement of $\mathrm{x}$ are spelled out (Embick 2010:51).

b. (Spell Out 2) Merge of cyclic $y$ triggers Spell Out of cyclic domains in the complement of $y$ (by SO1). For a cyclic domain headed by cyclic $x$ in the complement of $y$, this means that the complement of $x$, the head $x$ itself, and any edge ${ }^{+}$material attached to x's domain undergoes Vocabulary Insertion (Embick 2010:53).

The crucial point in Embick's proposal for Spell Out is that complements of phase heads sent to the interfaces need to consist of phasal or cyclic material. Not just every complement of a phase head is sent to the interfaces. As a consequence, in the structure in (39a), nothing is sent to the interfaces yet, since there is no cyclic head in the complement of $x_{1}$. Only the second f-affix $\left(x_{2}\right.$ in (39b)), which is itself a phasal head, has a cyclic domain $\left(\mathrm{x}_{1} \mathrm{P}\right)$ in its complement, which will be sent to the interfaces at the point that the f-affix merges.

a.

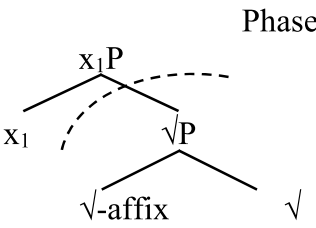

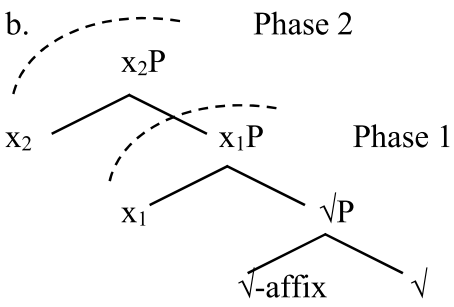

A summary of the different affixes in a single structure is given in (40).

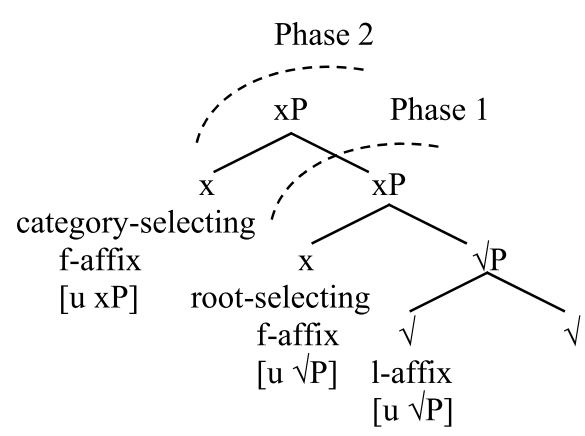

As a result, the first phase to be sent to the interfaces minimally consists of the root phrase (including one or more 1-affixes) plus the lowest root-selecting f-affix. Consequently, this part of the structure will be subject to cyclic phonological rules, including stress assignment in English (other phonological operations are discussed in Sect. 5.1.2). This particular implementation of locality predicts that all l-affixes and 
the lowest root-selecting f-affix are visible to the rules of stress assignment, because these constitute the first phase. Therefore, there is a class of f-affixes that is stress shifting, namely those that are root-selecting. Contrary to this, the category-selecting f-affixes cannot occur in this first phase, and therefore are invisible to the rules of stress assignment. In other words, this analysis derives both the difference between level-I and level-II affixes (the latter necessarily belonging to a higher phase), and between 1-affixes and f-affixes (the former but not the latter being categorially flexible).

Having laid out our proposal, let us now turn to some predictions that follow from it. The first prediction is that affixes that are both categorially flexible and stress neutral should be unattested. Since l-affixes and a root-selecting f-affix are always situated in the first phase, they are subject to stress rules. In order for an affix to occur outside the first phase, it needs to be a phase head itself, and therefore, it always spells out one and the same category and it cannot influence the stress pattern. As far as we can tell this prediction does not follow from Lowenstamm's proposal in any straightforward manner: a stress-neutral affix outside the first phase is still a root, and thus in principle flexible. Therefore, it is a coincidence in his proposal that all stress-neutral affixes are always non-flexible.

A second prediction that follows from the assumptions in (37) is the ordering of the affixes. Since 1-affixes select roots, they are predicted to be closest to the stem; root-selecting f-affixes attach to (simplex or complex) roots, and are, therefore, predicted to occur outside 1-affixes. Category-selecting f-affixes necessarily attach to categorized material, and consequently attach outside category-selecting f-affixes (and 1-affixes).

\subsection{Deriving the Dutch data}

In this section, we will show that the types of affixes empirically distinguished in Sect. 2 coincide with the three types of affixes that we theoretically distinguished in Sect. 4.1: level-Ia affixes correspond to l-affixes, level-Ib affixes correspond to root-selecting f-affixes, and level-II affixes correspond to category-selecting f-affixes. Finally, we will focus on the ordering of these three types, and we will show that the predictions made in the previous section are borne out.

In Sect. 2.1, we described a class of affixes that we preliminarily called level-Ia affixes and have the following properties: they are categorially flexible, they may attach to bound stems, and they are stress-shifting. Examples were the Dutch affixes -aat, -ief,-iel and -iek. This group of level-I affixes are l-affixes: they are categorially flexible because they are roots. They may attach to bound stems, since they are rootattaching. Recall from Sect. 2 that in some cases these affixes seem to attach to words. However, we claim that also in these cases these affixes attach to roots (as they always do) but the roots in question (such as diplomaat in (11)) have the same form as an independent word. Furthermore, they are stress-shifting because they appear in the first phase. This is illustrated in the structure in (41) (we will come back to the fact that the root-phrase $\sqrt{ }$ ALTERNATIEF needs to be categorized either as a noun or an adjective by a zero morpheme in Sect. 5.2.1). 
(41)

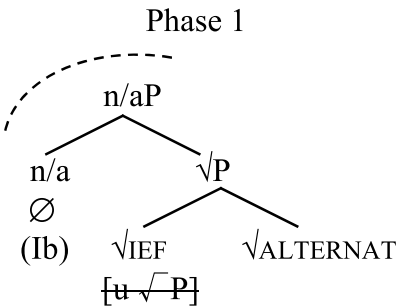

(Ia)

The level-Ib affixes described in Sect. 2.2 form the second group of the traditional level-I affixes. These affixes are stress-shifting and may attach to bound stems. However, in contrast to their level-Ia counterparts, they are not categorially flexible. This group of affixes corresponds to the class of root-selecting f-affixes. Their properties automatically follow: these affixes are categorially rigid because they spell out categorial heads; they may attach to bound stems because they have a feature $[u \sqrt{ } P]$, and they are stress-shifting because they only appear in the first phase. Just as in the case of level-Ia affixes, also level-Ib affixes may occasionally seem to attach to words rather than roots. As before, we claim that in these cases the form of the root coincides with the form of the word. Examples of this class of affixes given in Sect. 2.2 are -ig, -lijk, -iteit, and -eer. The structure of absurditeit 'absurdity' is given in (42).

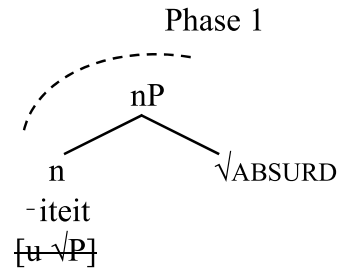

(Ib)

Third, we discuss the class of affixes that are traditionally referred to as levelII affixes. These affixes are non-flexible, only attach to categorized material (and not to bound stems), and are stress-neutral. Recall that the difference between root-selecting f-affixes and category-selecting f-affixes is that the former can attach to bound stems, whereas the latter cannot (i.e. it must always attach to categorized material). This final class of affixes corresponds to the categoryselecting f-affixes. The specific properties of these affixes are explained as follows: they are non-flexible because they spell out categorial heads; they only attach to categorized material because they have a feature $[\mathrm{u} x \mathrm{P}]$, and they are stress-neutral because they cannot appear in the first phase. Examples of these affixes given in Sect. 2.3 are the affixes -heid, -ing, and -sel. The structure of scheef-heid 'flexure' is given in (43). Note that the affix -heid always attaches to adjectives and that, therefore, the feature $[u x P]$ could be more specific, i.e. [u aP]. 


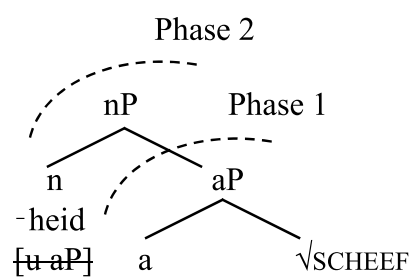

(II)

$\varnothing$

Above, we followed Embick (2010) in assuming that complements of phases are only sent to the interfaces if they contain a cyclic head (38). From this it follows that the affixes in the structures in (41) and (42) belong to the first phase: when the 1-affix -ief in (41) merges with the root, nothing is sent to the interfaces yet since there is no phasal head in its complement. The same holds for the root-selecting f-affix -iteit in (42): even though this f-affix is a cyclic head itself, it does not have any phasal or cyclic material in its complement, and therefore, it will not send its complement to PF (or LF). In contrast, the category-selecting faffix in (43), which is also a phasal head itself, has a cyclic domain in its complement, and consequently, it will send its complement to spell-out. This explains why the first two types of affixes are stress-shifting, whereas the latter is stressneutral.

The proposal in (38) rules out the existence of any affixes that are both categorially flexible and stress-neutral, since it is impossible that an affix both appears as an uncategorized element (necessary to be flexible), and outside the first phase (necessary to be stress-neutral). That is, if an affix occurs outside of the first phase, it needs to be a phase head itself, and therefore, it should always spell out one and the same category. To the best of our knowledge, stress-neutral flexible affixes are indeed unattested in Dutch. ${ }^{13}$

We have seen that the proposal in (38) makes the following predictions with regard to the ordering of the three types of affixes. L-affixes and root-selecting f-affixes attach to roots (due to their $[\mathrm{u} \sqrt{ } \mathrm{P}]$ feature). The latter derive non-roots and therefore should occur outside 1-affixes. Finally, category-selecting f-affixes always attach to categorized material, and therefore, occur outside all other affixes. These predictions can be summarized in a schema such as (44):

$$
\begin{array}{llll}
\text { S } & \text { A1 } & \text { A2 } & \text { A3 } \\
\text { STEM- } & \text { 1-affix- } & \text { root-selecting f-affix- } & \text { category-selecting f-affix }
\end{array}
$$

Above we showed that the three types of affixes that we empirically distinguished in Sect. 2 match the three types of affixes that we theoretically distinguished in Sect. 4.1. The empirically established order as was given in (20), here repeated as (45), thus follows from (44).

\footnotetext{
${ }^{13}$ However, among the unproductive affixes that we have not further taken into account, there seems to be one counterexample: the affix -(e)ling is stress-neutral and derives mostly nouns, but it also occurs in a few adjectives. Next to the pair dorp $\mathrm{N}$ 'village', dorp-eling N, village-LING, 'inhabitant of a village', we also find four adjectival cases in Nieuwborg (1969): mond-eling N/A, mouth-LING, 'oral', onder-ling A, under-LING 'mutual', plots-eling A, sudden-LING 'suddenly' and zonder-ling A/N ZONDER-LING 'weird'.
} 


$$
\begin{array}{llll}
\text { S } & \text { A1 } & \text { A2 } & \text { A3 } \\
\text { STEM- } & \text { level-Ia- } & \text { level-Ib- } & \text { level-II }
\end{array}
$$

The structure in (46) shows the ordering of the three types of affixes when they occur in the same word: -aal being a l-affix, -eer being a root-selecting f-affix and -ing being a category-selecting f-affix.

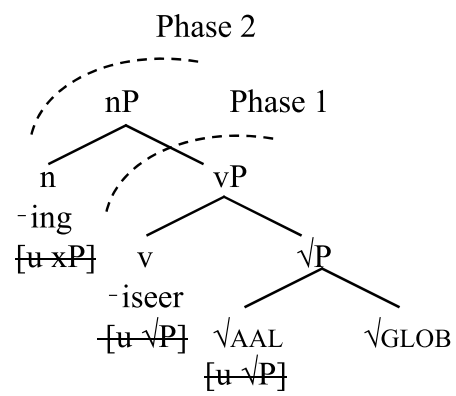

Finally, let us consider the possibility of affixes without specific selectional restrictions, as shown at the bottom of Table 2. Potential candidates for such affixes are the suffix -achtig, the suffix -schap, and the verbal f-prefixes (see Sect. 2) that attach both to roots and to categorized material. Let us first discuss the suffixes, after which we will focus more on the prefixes.

First, the affix -achtig should be analyzed as an f-affix because it always derives adjectives. If the affix -achtig is an f-affix without specific selectional restrictions, we expect the affix to be stress-shifting when it attaches to roots and stress-neutral when it attaches to categorized material. Let us consider the relevant data; some examples are given in (47b), where the affixes attaching to the bases in (47a) do not change the stress of their base. In some cases, however, the affix can change the stress and the meaning is more idiosyncratic. This can be seen in (47c).

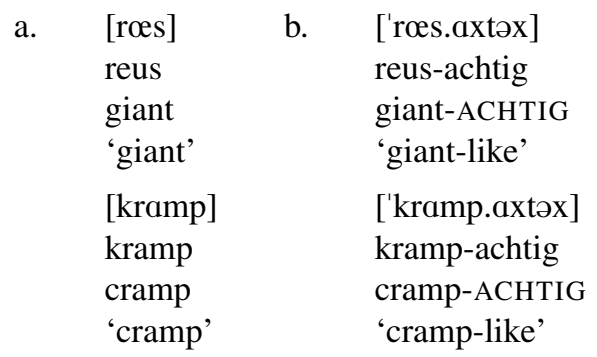
c. [rœ.'zaxtəx] reus-achtig giant-ACHTIG 'enormous' [kram. 'paxtəx] kramp-achtig cramp-ACHTIG 'strenuous'

There are systematic differences between the words belonging to those represented by the examples in (47b) and those represented by the examples in (47c). First of all, the stress pattern shifts under affixation of -achtig in (47c). Furthermore, the final consonant of the stem resyllabifies to the next syllable, where it is voiced. Finally, there are differences in meaning: the examples in (47b) are compositional, whereas the examples in $(47 \mathrm{c})$ render more idiosyncratic meanings.

From this we conclude that -achtig in (47c) attaches to a root, whereas the same affix attaches to a categorized word in (47b). This shows that -achtig is an f-affix 
that has the feature $[\mathrm{u} x]$ rather than a feature $[\mathrm{u} \sqrt{ } \mathrm{P}]$ or $[\mathrm{u} \mathrm{xP}]$. Once we allow this unspecified feature, the other aspects of the behavior of -achtig follow.

A similar reasoning holds for the suffix -schap, which we believe is, like-achtig, an f-affix without selectional restrictions. However, the evidence for this does not follow from the meaning and phonological characteristics of the affix, but from the meaning and ordering properties. First, the affix -schap conveys different meanings depending on the element to which it attaches. In words such as those in (48), the meaning is roughly 'the function of being x' (see Moortgat and van der Hulst 1981). The affix -schap in (49), on the other hand, has different properties. The word vriendschap for instance does not mean 'the function of being a friend' but rather means 'friendship' (instead of 'friendhood'). With respect to ordering, level-Ib affixes such as -lijk may attach outside this latter affix.

a. $\quad$ vader-schap
father-SCHAP ${ }_{\mathrm{A} 3}$
'fatherhood'
moeder-schap
mother-SCHAP
'motherhood'
maat-schap
pall-SCHAP
'type of firm'
vriend-schap
friend-SCHAP
'friendship'
b. $\quad$ *vader-schap-pelijk father-SCHAP ${ }_{\mathrm{A} 3}-\mathrm{LIJK}_{\mathrm{A} 2}$
*moeder-schap-pelijk mother-SCHAP ${ }_{\mathrm{A} 3}-\mathrm{LIJK}_{\mathrm{A} 2}$

b. maat-schap-elijk pall-SCHAP ${ }_{\mathrm{A} 1}-\mathrm{LIJK}_{\mathrm{A} 2}$ 'societal' vriend-schap-elijk friend-SCHAP ${ }_{\mathrm{A} 1}-\mathrm{LIJK}_{\mathrm{A} 2}$ 'friendly'

For these reasons, we assume that -schap in (48) attaches to categorized words, while it attaches to roots in (49). We therefore analyze -schap as an f-affix that has the feature $[\mathrm{u} \mathrm{x}]$. Note that we also predict that -schap, like -achtig, is stress-shifting when it attaches to roots and stress-neutral when it attaches to categorized material. However, such a stress-shift cannot be observed for the examples in (49), since the affixes attach to monosyllabic roots. ${ }^{14}$

Finally, for the Dutch prefixes, we showed in Sect. 2 that they behave like f-affixes with respect to flexibility, selectional requirements, and order. We also noted that these affixes show phonological behavior (syllabification, stress) that is not in accordance with their level-I status. This behavior is caused by different factors. With respect to the lack of resyllabification, we apply an argument by van Oostendorp (1994). Van Oostendorp observes that prefixes, contrary to suffixes, never trigger resyllabification. For example, in the Dutch word rodig 'reddish' the vowel-initial suffix -ig triggers resyllabification of the stem-final consonant in (50a). Contrary to this, the form ont-eer 'dishonor' (50b) with a vowel-initial verbal stem $(e e r)^{15}$ does not

\footnotetext{
${ }^{14}$ The only other instances of root-attached -schap are gemeenschap 'community' and wetenschap 'science', in which the predicted stress-shift cannot be observed because the final syllable of the root either is stressed (xə’men) or a schwa ('vetən), respectively.

${ }^{15}$ This eer form is a true base, meaning 'honor' and is not to be confused with the suffix -eer discussed in this subsection.
} 
undergo resyllabification, despite the fact that the syllabification on.teer would arguably be more optimal phonologically than the actual syllabification ont.Peer (with insertion of a glottal stop before the stem-initial vowel).

$\begin{array}{llll}\text { a. } & \begin{array}{l}\text { [rod] } \\ \text { rood } \\ \text { red } \\ \text { 'red' }\end{array} & \begin{array}{l}\text { [ro.dig] } \\ \text { rood-ig } \\ \text { red-IG } \\ \text { 'reddish' }\end{array} & * \text { [rod. əx] } \\ \text { b. } & \text { [er] } & \text { [ont-Per] } & * \text { [on.ter] } \\ & \text { eer } & \text { ont-eer } & \\ & \text { honor } & \text { ONT-honor } & \\ & \text { 'honor' } & \text { 'dishonor' }\end{array}$

In order to explain the difference between suffixes and prefixes, Van Oostendorp proposes that only syllables under construction may use material from neighboring syllables. Syllables that have been built in an earlier cycle cannot do so. The asymmetry between suffixes and prefixes now follows from the assumption that syllabification is cyclic, the first cycle being the morphological base.

In rodig, first the syllable rood [rod] is built. Next, we attach -ig and the syllabification rules apply to the cycle encompassing the form rodig. Since -ig [əx] is not an optimal syllable, it takes material from a neighboring syllable to satisfy the onset requirement. In the case of onteer, the syllable eer is first created. This syllable also violates the onset requirement but at the point of its creation there is no material present to optimize it. Later addition of ont- cannot be of any help since the syllable eer is already formed. This explains why we do not find resyllabification of prefixes despite their level-I status.

As for stress, we observe that most prefixes (be-, ver-, and $g e-$ ) have a schwa as their kernel vowel. Schwa is never stressed in Dutch, and therefore, it comes as no surprise that these prefixes never receive stress. However, there is one prefix, ont-, that does have a full vowel and nevertheless always remains stressless. We see no other explanation for this than to stipulate that ont-is somehow unstressable.

In this section, we have shown that the assumptions in (37) together account for the types of affixes that were distinguished in Sect. 2. We assume that rather than one type of affix, there are two types of affixes: l-affixes and f-affixes of which the f-affixes have different selectional requirements in the form of the features $[\mathrm{u} \sqrt{ } \mathrm{P}]$, $[\mathrm{u} x \mathrm{P}]$ or $[\mathrm{u} \mathrm{x}]$. Our next section will focus on some further empirical consequences and issues that follow from our analysis.

\section{Further consequences}

\subsection{Empirical consequences}

The proposal developed so far derives the observation that level-I affixes influence the stress-pattern of the base, whereas level-II affixes do not. Interestingly, if phasal theory is correct in assuming that the same phase sent to PF is also sent to LF, it is predicted that level-I affixes may influence the interpretation of the root, whereas level-II 
affixes may not. This prediction is not new, but mirrors the same prediction made by Lowenstamm (2015). Below, we will investigate this prediction and illustrate the idea with some Dutch examples.

A preliminary survey of other phonological and semantic properties that might follow from our proposal will be discussed in Sect. 5.1.1.

\subsubsection{Semantic interpretation}

It has been observed for English that level-II affixes have more compositional meanings in comparison to level-I affixes. For example, Kiparsky (1982b:136) observes:

"Derivational processes at later levels are semantically more uniform than those at earlier levels, where various specialized uses are prone to develop. [...] The greater semantic coherence of the general word-formation processes which are ordered at later levels is a consequence of their productivity (as suggested by Aronoff 1976:45)."

Arad (2003) also shows that the semantic interpretation of a root-domain is more susceptible to idiosyncrasies than the interpretation of domains that involve a categorial head.

Assuming that the phases for the PF and LF interfaces are the same, the division in types of affixes also has consequences for the semantic interface: the complement of the phasal head will not only be sent to PF, but also to LF, where it will be interpreted semantically (see for instance Marantz 2013 who shows that the locality constraints on contextual allosemy (LF) parallel those for contextual allomorphy (PF)). Recall that in our proposal, even though level-I affixes are split into two types, they are different from all level-II affixes in that they always occur below the first phasal boundary. We, therefore, predict that level-II affixes cannot influence the meaning of the material to which they attach, since they will be interpreted in a higher phase. Put differently, the interpretation of the material in the first phase has to take place before the material in one of the higher phases comes into play.

This prediction seems to be borne out, since in general the meaning of level-II affixes is compositional and does not give rise to idiosyncratic interpretations: categoryselecting f-affixes such as -heid do not give rise to idiosyncratic interpretations. In contrast, both root-selecting f-affixes and l-affixes (that together form the traditional level-I affixes) do give rise to idiosyncratic meanings. To illustrate, note for instance the difference between the category-selecting f-affix -baar and the 1-affixes -ief, -aal or -iek: the semantics of the former is transparent and constant; it always has a passive meaning that can be described as "being able to be V-ed" (where V replaces the meaning of the verb) (see e.g. de Haas and Trommelen 1993). The semantics of the latter affixes, however, is much more abstract and they have, among other interpretations, meanings such as 'of,' 'relating to,' 'engaged in,' and 'connected with.'

De Belder (2011) claims that the semantic interpretation of all affixes is malleable, which according to her shows that all affixes should be considered roots. If malleability of interpretation were indeed a property of all Dutch affixes, that would not fit our proposal, since we predict that only l-morphemes should display such malleability. However, we are not convinced by her arguments, for which the word schoon-heid 
'beauty' forms a central example. If indeed -heid is malleable, that would form a serious counterexample to our claim, since -heid is a category-selecting f-affix according to our analysis. This word is normally used as the abstract noun 'beauty' but it can also be used to refer to a female person ('a beauty'). According to De Belder, this shows that -heid has a malleable interpretation here. We believe that this argument does not show anything about the interpretation of -heid but does show that abstract nouns, whatever their internal structure, may be metaphorically used to refer to persons.

We, therefore, carefully conclude that our proposal seems to make the correct predictions as to the interpretation of affixes: 1-affixes are sensitive to the information in their root-phrase, whereas category-selecting f-affixes have a transparent compositional interpretation.

\subsubsection{Allomorphy}

Another prediction of our model is that allomorphs of roots can only be triggered by affixes that are spelled out in the same phase. Furthermore, allomorphs of particular affixes can only be triggered by material in the same phase. On the basis of Embick (2010) we expect all root-selecting f-affixes and l-affixes (level-I affixes) to be able to trigger allomorphy on the root, whereas cyclic category-selecting f-affixes would not be able to do so. It is important to note that category-selecting f-affixes that are not cyclic heads (not realizing a categorial head) are in the same phase as their complement. Consequently, they may have an effect on the realization of their complement. Hence, there is a difference in this respect between an affix such as -heid that realizes a categorial head and thus determines a phasal boundary, and the diminutive affix -tje that does not realize a categorial head, but merely spells out a non-categorial functional head.

As for affixal allomorphy, cyclic category-selecting f-affixes such as -heid, -ing, -dom, -schap, -sel, and -baar are always phonologically realized with one and the same form, whereas level-I affixes may have different manifestations. Furthermore, these latter affixes may also trigger different root allomorphs, whereas the former do not. The examples in (51a) show that -heid has no allomorphs dependent on the stem it attaches to. ${ }^{16}$ In (51b) and (51c), we see that the 1-affix -eel and the root-selecting f-affix -eer respectively do show different allomorphs depending on the root they attach to.

a.

\author{
-heid \\ ['sxonheit] \\ schoon-heid \\ beauty-HEID \\ 'beauty'
}

['jœystheit]
juist-heid
righ-HEID
'correctness'

['ardə $G$ heit] aardig-heid nice-HEID 'niceness'

\footnotetext{
${ }^{16}$ The affix -heid [heit] does have an allomorph [hed] which is (only) triggered by the plural affix -en. This latter affix is the realization of a functional head that does not introduce a phase-boundary. Consequently, in line with Embick (2010), this affix will be realized in the same phase as the affix -heid, and may, therefore, trigger an allomorphic variant of this affix.
} 


\begin{tabular}{|c|c|c|c|}
\hline \multirow[t]{5}{*}{ b. } & -eel & & \\
\hline & [perso'nel] & [1ntəlekty'el] & [poten'sjel] \\
\hline & person-eel & intellect-ueel & potent-ieel \\
\hline & person-EEL & intellect-EEL & POTENT-EEL \\
\hline & 'personnel' & 'intellectual' & 'potential' \\
\hline \multirow[t]{5}{*}{ c. } & $-e e r$ & & \\
\hline & [tampo'ner] & [normali'zer] & [aksenty'er] \\
\hline & tampon-eer & normal-iseer & accent-ueer \\
\hline & tampon-EER & normal-EER & accent-EER \\
\hline & 'stamping' & 'to normalize' & 'to accentuate' \\
\hline
\end{tabular}

Furthermore, the 1-affixes may also show different allomorphs depending on the affix that attaches higher in the structure, but still in the same phase. Example (52) gives some examples where the root-selecting f-affix -iteit triggers allomorphy in -iek and -eel respectively.

\begin{tabular}{|c|c|c|c|}
\hline a. & -iek & & \\
\hline & ['kanon] & [kano'nik] & [kano'nisiteit] \\
\hline & canon & canonn-iek & canon-ic-iteit \\
\hline & & canon-IEK & canon-IEK-ITEIT \\
\hline & 'canon' & 'canonical' & 'canonicity' \\
\hline b. & $-e e l$ & & \\
\hline & [intəl'ckt] & [intəl\&kt'yel] & [intəlektyalit'cit] \\
\hline & intellect & intellect-ueel & intellectu-al-iteit \\
\hline & & intellect-EEL & intellect-EEL-ITEIT \\
\hline & 'intellect' & 'intellectual' & ‘intellectuality’' \\
\hline
\end{tabular}

Besides these examples of affixal allomorphy, cases of root allomorphy also occur. The relevance of these examples is that this type of allomorphy may only be triggered by affixes that occur in the same phase as the root. Below, we give examples illustrating that category-selecting f-affixes do not trigger any root-allomorphy, whereas 1-affixes and root-selecting f-affixes do.

Booij (1997) provides a large number of examples of what he calls stemallomorphy. All these examples involve l-affixes or root-selecting f-affixes. Some examples (from Booij 1997:36) illustrate this generalization; the stress shift that may be observed in these examples is a further corroboration of the status of these affixes.

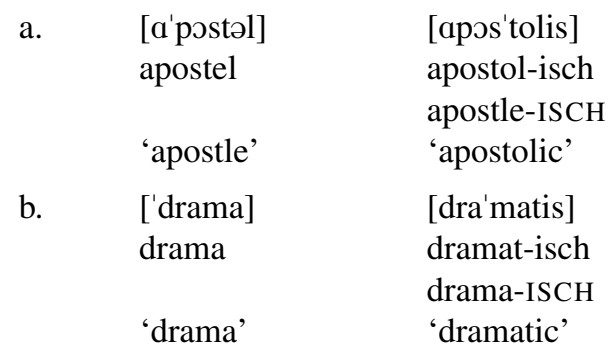




$\begin{array}{lll}\text { c. } & \text { ['fœyksi] } & \text { [fœyksjo'nel] } \\ & \text { functie } & \begin{array}{l}\text { function-eel } \\ \text { function-EEL } \\ \text { 'functional' }\end{array} \\ \text { d. } & \begin{array}{l}\text { [or'kest] } \\ \text { orkest }\end{array} & \begin{array}{l}\text { [orke'strer] } \\ \text { orkestr-eer } \\ \text { orchestra-EER } \\ \end{array} \\ & \text { 'orchestra' } & \text { orchestrate' }\end{array}$

Note that the same roots do not show this allomorphy when a categorizing f-affix attaches, as can be seen in (54), where we use the affixes -achtig, and the diminutive affix (-tje) to illustrate this point.
a. apostel-achtig, apostel-tje
[apostəl]
b. drama-achtig, drama-tje
[drama]
c. functie-tje
[fœyksi]
d. orkest-achtig, orkest-je
[orkest]

Briefly summarizing, although there is much more to say about allomorphy and what may trigger allomorphs to occur under what specific conditions, we believe that the above observations lend initial support to our proposal.

\subsection{Further issues}

In this section we spell out some theoretical implications and consequences of the proposal laid out in Sect. 4. First in Sect. 5.2.1 we will go into the specific consequences of the idea that some affixes select for a categorized structure. In Sect. 5.2.2, we discuss why the observed categorial flexibility is limited to adjectives and nouns.

\subsubsection{Empty heads}

Crucial to our proposal is the idea that some affixes select a categorized structure, whereas other affixes select root structures. However, the difference between the selected structures is not always visible at the surface. Consider the data in (55).
a. univers-eel-heid
UNIVERS-EEL IA - HEID $_{\text {II }}$
'universality'
a'. univers-al-iteit
UNIVERS-EEL IA $_{\text {ITEIT }}$ IB 'universality'
b. kandid-aat-schap
KANDID-AAT IA $-\mathrm{SCHAP}_{\mathrm{II}}$
'candidacy'
c. perspect-ief-loos
PERSPECT-IEF-LOOS
'without prospects'
d. agress-iev-eling
AGRESS-IEF-ELING
'someone who is aggressive'
b'. kandid-aat-uur
KANDID-AAT ${ }_{\text {IA }}-\mathrm{UUR}_{\mathrm{IB}}$ 'candidacy'


In (55a), (55b) a root-selecting l-affix (resp. -eel and -aat) attaches to the root, after which a category-selecting f-affix (resp. -heid and -schap) attaches to the complex root. These latter affixes search for a category, so the question arises how these complex roots are able to fulfill the selectional requirements of these affixes. Similarly, we would also predict that -loos and -eling in (55c)-(55d) would behave as stressshifting affixes here if they attach immediately above the root phrase. Being the first categorizing heads above the root structure, Embick's (2010) theory would predict that these affixes would be spelled out in the same domain as the root. However, -loos and -eling are not stress-shifting, and apparently, their selectional requirements are fulfilled somehow by the structure to which they attach.

The answer to this problem must be that there is a categorial head between the root structure and the category-selecting affix that is not spelled out. That is, we assume that the structure of universeelheid 'universality' is as in (56):

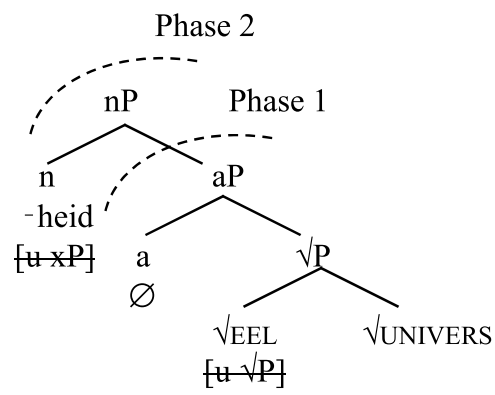

There are a few additional considerations that lend further support to this analytical move. Recall that some category-selecting f-affixes require a particular category in their complement; e.g. -heid selects adjectives. Therefore, it will lead to an ungrammatical result if the affix attaches to something other than an adjective. Secondly, and this brings us to the relation between the root phrase and the first categorial head, a root phrase needs to be categorized anyway. Therefore, this move is independently motivated by complexes of the form $[\sqrt{ }, 1$-affix $]$, that freely occur as either nouns or adjectives, such as e.g. intellect-uee $l_{\mathrm{A} / \mathrm{N}}$ 'intellectual' or $k w a d r-a a t_{\mathrm{N}}$ 'square'. Material that solely consists of root elements can only be used for further syntactic computations if it is categorized. Therefore, probably by general principle, these structures will have to be categorized, and may only surface in case a categorial head attaches above the root phrase. Thus, a syntactic head is always needed in between the root phrase and a category selecting f-affix.

\subsubsection{The lack of complex verbs}

As a consequence of our proposal, 1-affixes are flexible between different syntactic categories. However, it turns out that all l-affixes in Dutch are only flexible between nouns and adjectives. So, one may ask why the category verb is never included in such flexibility. We believe that it is not a fundamental property of the (Romance) affixes that they are only flexible between adjective and nouns, but that it is a result of some other orthogonal property of Dutch morphology. As it turns out, the only 
way of forming verbs with a level-I affix is with the affix -eer, or its allomorph -iseer. Some examples are given in (57).
a. function-eer FUNCTION-EER
'to function'
b. caramell-iseer
caramel-ISEER
'to caramelize'
c. argu-ment-eer
ARGU-MENT-EER
'to argue'

\author{
control-eer \\ control-EER \\ 'to control' \\ alfabet-iseer \\ alfabet-ISEER \\ 'to alphabetize' \\ infant-iel-iseer \\ INFANT-IEL-ISEER \\ 'to become infantile'
}

Whether the base only consists of a root, or a root plus an l-affix (as in (57c)), any verbal head that attaches to this domain is spelled out with the affix -eer (or its allomorph -iseer). In other words, -eer could be considered 'greedy': it consumes the space that would be necessary to witness any affixes that show flexible behavior involving the category verb. So, it is this behavior of -eer that is completely independent of our proposal that prevents us from seeing any 'fully flexible' affixes.

\section{Conclusions}

Above we have presented a proposal that builds on Lowenstamm's idea that affixes are roots. However, we propose that not all affixes are roots, but only the ones showing flexible behavior. Important empirical support for this view comes from the observation that all flexible affixes in Dutch are stress-shifting, while all stress-neutral affixes are rigid. This correlation between these properties remains unexplained in Lowenstamm's proposal. To us, this correlation shows that the distinction between lexical morphemes and functional morphemes also holds in the domain of derivational affixes: Lexical morphemes enter the root domain where they may influence phonological and semantic properties of the resulting complex, functional morphemes attach on top of this complex. This implies that in our typology of elements, we have added to the class of roots a set of elements that need a base to attach to (1-affixes). L-affixes thus belong to the same class of elements that traditionally have been called bound roots, such as $\sqrt{ }$ DEMOCR in democracy and democrat. They need other material to attach to in the root-domain in order to surface.

A special position is taken by those functional morphemes that are the first to dominate the root phrase. As a consequence of the theory of spell-out adopted here (Embick 2010), these affixes will be spelled out in the same domain as the root, and therefore these derivational affixes will also show a phonological and semantic effect on the root complex, in a way making the above correlation between stress-sensitivity and flexibility a little more complex.

The lexical-functional distinction is not the only division between different types of derivational affixes. Following Lowenstamm (2015), we have proposed that functional derivational affixes (spelling out categorial heads) should be distinguished on 
Table 2 Affix types (repeated)

First phase
a. 1-affix

$[\mathrm{u} \sqrt{ } \mathrm{P}]$ b. f-affixes

$[\mathrm{u} \sqrt{\mathrm{P}}]$

f-affix [u x]
Later phases

f-affixes

[u xP]

the basis of their different selectional properties. Some affixes require a root in their complement, others require a (specific) categorized structure, and others yet simply do not care. This results in the following typology of affixes, as can be seen in Table 2, repeated above.

We have shown that the above typology makes the correct predictions for the behavior of the Dutch affixes. Further research should make clear whether the typology can also successfully be applied to other languages. As far as we can see, the proposal makes the correct predictions for English affixes, and a first investigation into the derivational affixes of French also seems to point in the same direction (Don et al. 2015).

Acknowledgements This paper has benefited greatly from comments and discussions with Jonathan Bobaljik, Ksenia Bogomolets, Marijke de Belder, David Embick, Laura Kalin, Caitlin Meyer, Ad Neeleman, Andrew Nevins, Fred Weerman and four anonymous reviewers. Versions of this paper have been presented at de Morfologiedagen 2013 (Leeuwarden), the UCL colloquium in March 2014, the International Morphology Meeting 2014 (Budapest), and North East Linguistics Society 2014 (Boston).

Open Access This article is distributed under the terms of the Creative Commons Attribution 4.0 International License (http://creativecommons.org/licenses/by/4.0/), which permits unrestricted use, distribution, and reproduction in any medium, provided you give appropriate credit to the original author(s) and the source, provide a link to the Creative Commons license, and indicate if changes were made.

\section{Appendix 1}

The Dutch affixes considered in our investigation do not include those affixes that can only be found in one or two words. These include the Latin and Greek suffixes -ale (univers-ale 'universal'), -alis (plur-alis 'plural'), -ix (append-ix 'appendix'), -egge (diev-egge 'thief-FEM'), -ma (lemm-a 'lemma'), -ex (ind-ex 'index'), -ioen (vis-ioen 'vision', kamp-ioen 'champion', pens-ioen 'pension' and leg-ioen 'legion'), -and (heil-and 'savior'), -en (Christ-en 'Christian', heid-en 'pagan'), -eut (pharmac-eut 'pharmaceut'), -urg (dramat-urg 'dramaturge'), -oor (stucad-oor"), -ak (mani-ak 'maniac'), -ied (Ajax-ied 'Ajax-fan'), -ka (judo-ka 'judoka'), -rice (direct-rice 'director-FEM'), -euse (frit-euse 'fryer'), and -rix (ment-rix 'mentrix'). We have too little evidence that these words are truly morphologically complex. However, we note that these affixes would not cause any problem for our analysis if we would have included them.

We also excluded those suffixes that always occur in words that only denote certain chemical substances, such as -ase (lact-ase 'lactase', sachar-ase 'sucrase'), -ine (cafe-ïne 'caffeine', coca-ïne 'cocaine'), -ica (alcohol-ica 'alcohols', hypnot-ica 
'hypnotics'), -aan (oct-aan 'octane', prop-aan 'propane'), -aat (chlor-aat 'chlorate', nitr-aat 'nitrate', fosf-aat 'phosphate'), -iet (chlor-iet 'chlorite', dynam-iet 'dynamite'), -een (benz-een 'benzene', ars-een 'arsenic'), -ium (pluton-ium 'plutonium'), -ide (fluor-ide 'fluoride', brom-ide 'bromide'), -oide (cellul-oide 'celluloid', alkaloide 'alkaloid'), -ose (cellul-ose 'cellulose', galact-ose 'galactose'), -ol (methan-ol 'methanol', fen-ol 'phenol'), -yl (vin-yl 'vinyl', meth-yl 'methyl'), -itis (bronch-itis 'bronchitis') and -antia (lax-antia 'laxatives', stimul-antia 'stimulants').

\section{Appendix 2}

Level-Ia affixes: -aal, -aat, -ief, -iek, -iel-(i)aal, -(i)aan, -air (-itair, -onair), -ant, -é, -(o)ide, -(i)eel, -ees, -ent, -(en)ier, -iet, -oir, -t, and -(u)eel.

Level-Ib affixes: - $(a)(e)(i) m e n t$ (orna-ment 'ornament'), -abel (-ibel), (respectabel 'respectable') -age (camouflage 'camouflage'), -aire, -ares, -aris, -arium, -asme, -ast, -een, -eer, -erie, -esse, -ette, -eur, -eus, -ica, -icus, -ie, -ien, -ier, -ieur, -ijn, -ij, -in, -isch, -isme, -ist, -ium, -oot, -or, -tuur (-(a)(i) tuur), -um, -ure, and -us (-endus, and -andus).

Level-II affixes: -aard, -achtig, -ade, -baar, -de, -dom, -er, -erd, -erig, -erik, -erwijs, -gewijs, -halve, -iter, -(e)ling, -(e)loos, -(t)(e)nis, -schap, -st, -ster, -t, -te, -waarts, -weg, and -zaam.

\section{References}

Arad, Maya. 2003. Locality constraints on the interpretation of roots: The case of Hebrew denominal verbs. Natural Language and Linguistic Theory 21: 737-778.

Aronoff, Mark. 1976. Word formation in generative grammar. Cambridge: MIT Press.

Aronoff, Mark, and Shikaripur N. Sridhar. 1983. Morphological levels in English and Kannada or atarizing Reagan. In Papers from the parasession on the interplay of phonology, morphology and syntax, eds. John F. Richardson, Mitchell Marks, and Amy Chukerman, 3-15. Chicago: Chicago Linguistic Society.

Booij, Geert E. 1977. Dutch morphology: A study of word formation in generative grammar. Foris: Dordrecht.

Booij, Geert E. 1995. The phonology of Dutch. Oxford: Clarendon.

Booij, Geert E. 1997. Autonomous morphology and paradigmatic relations. In Yearbook of morphology 1996, eds. Geert E. Booij and Jaap van Marle, 35-55. Dordrecht: Kluwer Academic.

Borer, Hagit. 2005a. In name only: Structuring sense. vol. I, Oxford: Oxford University Press.

Borer, Hagit. 2005b. The normal course of events: Structuring sense, vol. II. Oxford: Oxford University Press.

Chomsky, Noam. 2000. Minimalist inquiries. In Step by step: Essays on minimalist syntax in honor of Howard Lasnik, eds. Roger Martin, David Michaels, and Juan Uriagereka, 89-156. Cambridge: MIT Press.

Chomsky, Noam. 2001. Derivation by phase. In Ken Hale: A life in language, ed. Michael Kenstowicz, 1-52. Cambridge: MIT Press.

Chomsky, Noam, and Morris Halle. 1968. The sound pattern of English. New York: Harper \& Row.

Belder, Marijke De. 2011. Roots and affixes, eliminating lexical categories from syntax. PhD diss., Utrecht University.

Don, Jan. 2015. Vrouwelijke persoonsnamen in het Nederlands. Nederlandse Taalkunde 20(3): 315-337.

Don, Jan, Petra Sleeman, and Thom Westveer. 2015. Three types of suffixes in French: Discarding the learned/non-learned distinction. In Linguistics in the Netherlands 2015, eds. Björn Köhnlein and Jenny Audring, 33-47. Amsterdam: Benjamins. 
Embick, David. 2010. Localism versus globalism in morphology and phonology. Cambridge: MIT Press.

Embick, David. 2014. Phase cycles, $\phi$-cycles, and phonological (in)activitiy. In The form of structure, the structure of form, eds. Sabrina Bendjaballah, Noam Faust, Mohamed Lahrouchi, and Nicola Lampitelli, 271-287. Amsterdam: Benjamins.

Fabb, Nigel. 1988. English suffixation is constrained only by selectional restrictions. Natural Language and Linguistic Theory 6: 527-539.

Giegerich, Heinz. 1999. Lexical strata in English: Morphological causes, phonological effects. Cambridge: Cambridge University Press.

Haas, Wim de, and Mieke Trommelen. 1993. Morfologisch handboek van het Nederlands: een overzicht van de woordvorming. 's-Gravenhage: SDU Uitgeverij.

Halle, Morris, and Alec Marantz. 1993. Distributed morphology and the pieces of inflection. In The view from the building 20, eds. Ken Hale and Samuel J. Keyser, 111-176. Cambridge: MIT Press.

Halle, Morris, and Karuvannur P. Mohanan. 1985. Segmental phonology of modern English. Linguistic Inquiry 16: 57-116.

Harley, Heidi. 2009. Compounding in distributed morphology. In Oxford handbook of compounding, eds. Rochelle Lieber and Pavel Stekauer, 129-144. Oxford: Oxford University Press.

Harley, Heidi, and Rolf Noyer. 1999. State-of-the-article: Distributed morphology. Glot International 4(4): 3-9.

Hulst, Harry G. van der. 1984. Syllable structure and stress in Dutch. Dordrecht: Foris.

Kager, René. 1989. A metrical theory of stress and destressing in English and Dutch. PhD diss., Utrecht University.

Kager, René. 2000. Stem stress and peak correspondence in Dutch. In Optimality theory: Phonology, syntax and acquisition, eds. Joost Dekkers, Frank van der Leeuw and Jeroen van der Weijer, 121150. Oxford: Oxford University Press.

Kiparsky, Paul. 1982a. From cyclic phonology to lexical phonology. In The structure of phonological representations (I), eds. Harry van der Hulst and Norval Smith, 131-175. Dordrecht: Foris.

Kiparsky, Paul. 1982b. Word-formation and the lexicon. In Mid-America linguistics conference, ed. Frances Ingemann. Lawrence: University of Kansas.

Kiparsky, Paul. 1985. Some consequences of lexical phonology. Phonology Yearbook 2: 85-138.

Langeweg, Simone. 1985. Non-native suffixes and stress in Dutch. In Linguistics in the Netherlands, eds. Hans Bennis and Frits Beukema, 101-110. Dordrecht: Foris.

Lowenstamm, Jean. 2015. Derivational affixes as roots: Phasal spell-out meets English stress shift. In The syntax of roots and the roots of syntax, eds. Artemis Alexiadou, Hagit Borer, and Florian Schäfer, 230-259. Oxford: Oxford University Press.

Marantz, Alec. 1997. No escape from syntax: Don't try morphological analysis in the privacy of your own lexicon. In 21st Annual Penn Linguistics Colloquium: Penn Working Papers in Linguistics 4(2), eds. Alexis Dimitriadis, Laura Siegel, Clarissa Surek-Clark, Alexander Williams, 201-225.

Marantz, Alec. 2001. Words and things. Ms., MIT.

Marantz, Alec. 2007. Phases and words. In Phases in the theory of grammar, ed. Sook-Hee Choe, 191-222. Seoul: Dong In.

Marantz, Alec. 2013. Locality domains for contextual allomorphy across the interfaces. In Distributed morphology today: Morphemes for Morris Halle, eds. Ora Matushansky and Alec Marantz, 95-116. Cambridge: MIT Press.

Marvin, Tatjana. 2003. Topics in the stress and syntax of words. PhD diss., MIT.

Marvin, Tatjana. 2013. Is word structure relevant for stress assignment? In Distributed morphology today, eds. Ora Matushansky and Alec Marantz, 79-94. Cambridge: MIT Press.

Moortgat, Michael, and Harry G. van der Hulst. 1981. Geïnterpreteerde morfologie. Glot 4: 179-214.

Nieuwborg, E. R. 1969. Retrograde woordenboek van de Nederlandse taal. Antwerpen: Uitgeverij Plantyn.

Oostendorp, Marc van. 1994. Affixation and integrity of syllable structure in Dutch. In Linguistics in the Netherlands, eds. Reineke Bok-Bennema and Crit Cremers, 151-162. Amsterdam: Benjamins.

Schultink, Henk. 1980. On stacking up affixes, mainly in Dutch words. In Linguistic studies offered to Berte Siertsema, eds. Dick J. van Alkemade, Anthonia Feitsma, Willem J. Meys, Pieter van Reenen, and J.J. Spa, 229-242. Amsterdam: Rodopi.

Shwayder, Kobey. 2015. Words and subwords: Phonology in a piece-based syntactic morphology. PhD diss., UPenn.

Selkirk, Elisabeth. 1982. The syntax of words. Cambridge: MIT Press.

Siegel, Dorothy. 1974. Topics in English morphology. PhD diss., MIT. 
Trommelen, Mieke, and Wim Zonneveld. 1986. Dutch morphology: Evidence for the right-hand head rule. Linguistic Inquiry 17(1): 147-169.

Trommelen, Mieke, and Wim Zonneveld. 1989. Klemtoon en metrische fonologie. Bussum: Coutinho. Zwarts, Frans. 1975. -aar, -arij, -sel en -te. TABU 6: 9-23.

Williams, Edwin. 1981. On the notions "Lexically Related" and "Head of a Word". Linguistic Inquiry 12: 254-274. 